\title{
Understanding regional variation in entrepreneurial activity and entrepreneurial attitude in Europe
}

\author{
Niels Bosma • Veronique Schutjens
}

Received: 9 March 2009 / Accepted: 13 March 2010 / Published online: 21 May 2010 (C) The Author(s) 2010. This article is published with open access at Springerlink.com

\begin{abstract}
Differences in entrepreneurial activity and entrepreneurial attitude are substantial and persistent across nations and regions. However, studies on entrepreneurship that encompass regions and countries at the same time are lacking. This paper explains both national and regional differences in entrepreneurial attitude and activity for 127 regions in 17 European countries, based on Global Entrepreneurship Monitor (GEM) data. We reveal the importance of institutional factors and economic and demographic attributes to variations in regional entrepreneurial attitude and activity. Our findings point at the relevance of distinguishing between components of entrepreneurial attitudes, i.e. fear of failure in starting business, perceptions on start-up opportunities and self-assessment of personal capabilities to start a firm. We find different determinants of these components, suggesting that they reflect different aspects of entrepreneurial attitude. In explaining regional prevalence rates of phases in entrepreneurial activity (nascent, baby business, established business) we find significant contributions of entrepreneurial attitude components. Urban regions and regions with high levels of nearby start-up examples show relatively high rates of early-stage entrepreneurship. A large number of start-up procedures does not discourage early-stage entrepreneurship.
\end{abstract}

JEL Classification $\mathrm{M} 13 \cdot \mathrm{O} 18 \cdot \mathrm{R} 12$

\footnotetext{
N. Bosma $\cdot$ V. Schutjens $(\varangle)$

Urban and Regional research centre Utrecht, Department of Economic Geography,

Faculty of Geosciences, Utrecht University, Utrecht, The Netherlands

e-mail: v.schutjens@geo.uu.nl

N. Bosma

e-mail: n.bosma@geo.uu.nl
} 


\section{Introduction}

It is now widely recognized that regional variation in entrepreneurship is significant and persistent, and often even exceeds national differences (Sternberg 2004; Fritsch and Mueller 2006; Tamásy 2006; Bosma and Schutjens 2009a). This applies to both entrepreneurial attitude and actual entrepreneurial activity. Observed actual entrepreneurship rates, whether early stage entrepreneurship and established business rates, show high regional variation. Bosma and Schutjens (2009a) have shown that especially the prevalence rate of nascent and young businesses varies widely across regions. Entrepreneurial attitudes, which at the individual level are captured by a combination of fear of failure, the perception of regional start-up opportunities and having knowledge and skills to set up a firm, also differ between regions.

The relevance of relating entrepreneurial attitudes to entrepreneurial behaviour follows from the findings of an emerging set of empirical papers at different spatial levels. For example, at the national level, Wennekers et al. (2007) established a link between uncertainty avoidance and business ownership. At the regional level, Davidsson and Wiklund (1997) found a significant but marginal contribution of cultural differences in explaining regional variation in new firm formation within Sweden. At the individual level, Lückgen et al. (2006), Arenius and Minniti (2005) and Tamásy (2006) found evidence of a very strong positive effect of entrepreneurial attitudes on entrepreneurial behaviour. In her empirical study, Tamásy (2006) revealed a significant contribution of several entrepreneurial attitude indices to entrepreneurial activity, next to more traditional explanations.

In an earlier study, the spatial patterns of the indices of entrepreneurial attitude and activity in EU countries and regions are mapped and discussed (Bosma and Schutjens 2009a). What is missing thus far is the understanding of the spatial patterns of both entrepreneurial attitude and activity. The purpose of the present paper is to explain these spatial patterns in an empirical analysis, using indicators of both early-stage entrepreneurial activity and attitude across 127 regions and 17 countries in Europe. Thus, next to describing the spatial patterns, we empirically test the influence of national and regional conditions on entrepreneurial attitude and activity.

The remainder of the paper is organized as follows. We first present the literature on explanations of regional variations in entrepreneurial attitude and activity. From this review we derive regional and national indicators of determinants of regional entrepreneurship rates, and are able to conceptualize the differential impact of regional and national conditions on both entrepreneurial attitude and activity. In Sect. 3 we describe our data and methodology. In Sect. 4 we present the results of the analyses on entrepreneurial attitude and activity. We conclude with a discussion based on the confrontation of our findings with the literature overview and our preliminary expectations. Here we give special attention to the difference between entrepreneurial attitude and actual entrepreneurial behaviour, which results in the share of people that for some reason does not turn (latent) entrepreneurial intentions into reality. This so-called 'Untapped Entrepreneurial Potential (UEP)'-index relates to people who think they have the skills and see good opportunities for start-ups in their region, but who are nevertheless not involved in entrepreneurship. 


\section{Literature review on regional entrepreneurial attitude and activity rates}

In explaining differences in regional entrepreneurial attitudes and activities, one has to take into account that closely intertwined micro- and macro phenomena are at play. People have individual values, preferences, assess their own capabilities, see opportunities and make decisions with respect to entrepreneurship. These decisions may be conditioned and influenced by individual personality, personal or household characteristics, but also by local availability of business premises, regional market growth, and - at the macro level—socio-cultural attitudes towards firm ownership or even regulatory impediments. As a consequence, spatial differences in entrepreneurial attitude and activities may be the result of both a regional demography (an overrepresentation of groups of individuals with high entrepreneurial spirits or involvement in entrepreneurial behaviour), specific regional economic attributes (f.i. market opportunities), and an institutional component. Following North (1994) in his famous work on institutions, we thereby distinguish between informal institutions (culture, values, norms) and formal institutions (rules, laws, regulations). At the individual level, the interdependency between personal preferences, values and behaviour and (external) regional opportunities or national regulations can hardly be disentangled. For example, traditional strict national regulations on new firm registration may discourage people to even think of starting a firm, (un)consciously anticipating on regulatory obstacles in later stages of firm formation (see Freytag and Thurik 2007 who combined both cultural and regulatory effects in analysing latent and actual entrepreneurship). In fact, not only actual administrative procedures or financial regulations are important, but also people's perception of these financial or administrative barriers (Grilo and Irigoyen 2006).

An initial general conclusion from the literature review is that many studies directly relate (formal and/or informal) institutions to entrepreneurship activities and thus either leapfrogging entrepreneurial attitudes altogether or referring to it implicitly as a natural condition for actual entrepreneurial behaviour. Uhlaner and Thurik (2007), for instance, found a significant negative effect of postmaterialism (attaching low value to money) on firm formation. Wennekers et al. (2007) concluded that uncertainty avoidance is negatively correlated to business ownership. And also Davidsson and Wiklund (1997) directly related general cultural values to new firm formation. Blanchflower (2000) linked national differences in labour market regulations to self-employment, as did Van Stel et al. (2007). However, we argue that institutional conditions influence entrepreneurial behaviour not directly, but indirectly, by affecting entrepreneurial attitudes first. This is in line with Beugelsdijk (2007) who recently showed that self-employed differ significantly from others with respect to values in society and especially economy. Furthermore, the link between entrepreneurial attitude and actual behaviour is not straightforward, as many people do not realize their ambitions (see Grilo and Irigoyen 2006). It should therefore be emphasized that in this paper we try to disentangle entrepreneurial attitudes and entrepreneurial activities, following the work of Grilo and Irigoyen (2006) and Tamásy (2006).

Although the link between entrepreneurial attitudes and entrepreneurial behaviour is being acknowledged, thus far a conceptual and empirical explanation of the regional variation in both indices is lacking, especially with respect to entrepreneurial spirits. 
2.1 Evidence on regional variation in entrepreneurial attitude and its explanations

There is empirical evidence of large cross-country differences in entrepreneurial attitudes. Both the annual GEM and Eurobarometer data (see for GEM Bosma et al. 2009a; for Eurobarometer Grilo and Thurik 2006) demonstrated that entrepreneurial attitude differs substantially between countries. Especially inhabitants of Southern Europe, the UK and Ireland show relatively high self-employment preferences. Although within the EU considerable variation exists, the EU is especially concerned about the apparent difference in entrepreneurial attitudes between EU-countries and the United States: on average, $45 \%$ of the EU-citizens prefer to be self-employed whereas this percentage is $67 \%$ for the US (European Commission 2003). ${ }^{1}$ With respect to entrepreneurial attitudes at the regional level, the number of studies is rather limited. Beugelsdijk and Noorderhaven (2004) derived an index relating to 'enterprise culture', which, however, only indirectly links to entrepreneurship, and found significant differences between European regions. Enabled by the extensive sample size of the REM surveys in 2001 and 2003 in Germany (REM project ${ }^{2}$ ), Tamásy (2006) studied regional entrepreneurship in Germany and also reported significant regional differences in entrepreneurial attitudes. Sternberg and Litzenberger (2004) found considerable regional differences in entrepreneurial attitudes, as the latter positively related to the regional number and size of clusters.

At the macro level, entrepreneurial attitude can be regarded as a specific component of cultural attitude, reflecting persistent beliefs, norms and values. Culture is seen as "...the collective programming of the mind that distinguishes the members of one group or category from another...” (Hofstede 2001, p.1). This collective programming influences values, norms and beliefs - and ultimately also behaviour - at the individual level. Using a regional database on values and norms for 55 European regions in the period 1990-1999, Beugelsdijk et al. (2006) showed that regional variation in cultural attitudes are significant and persistent over time (see also Davidsson and Wiklund 1997). This persistency in regional cultural patterns is due to long term cultural heritages (Inglehart and Baker 2000), which can be both regional, national or even supra-national. This would call for a regional approach to Hofstede's measurement of national cultural values (Hofstede 2001), in which different spatial scales are acknowledged. In a critical assessment of Hofstede's indices, Baskerville (2003, p.3) states that '...cultures do not equate with nations...'. As some regions may cross national borders, this leaves room for the existence of both broad supra-national cultures and specific regional or even local values and beliefs. Applying this view to economy and entrepreneurship, at the supra-national level Hall and Soskice (2001) discerned the liberal market regime versus the coordinated market regime, reflecting two utterly different market systems. At the regional level, the traditional work of Weber (1904)

\footnotetext{
1 The difference appears to be largely caused by Germany and France.

2 In Spain and Germany the national Global Entrepreneurship Monitor was extended, leading to large data sets on entrepreneurial activities and attitudes at the regional level (see for Germany the Regional Entrepreneurship Monitor REM project described in Bergmann et al. (2002); for Spain De La Vega Pastor et al. 2005).
} 
highlighted the existence of several regional societies, in which business ownership and entrepreneurship is valued lower than elsewhere.

As argued earlier, in explaining variation in entrepreneurial attitudes at the regional level we have to discern demographic, economic and institutional (formal and informal) effects. In accounting for composition effects, we follow Bergmann et al. (2002), Bergmann (2005) and Tamásy (2006) who analysed individual characteristics in explaining entrepreneurial values and beliefs. It is argued that younger people have quite different attitudes than older people, especially with respect to self-assessment and view on society (Jonsson and Flanagan 2000; Kirkpatrick Johnson 2001). In general, they spot more (economic) opportunities and show higher preferences to become self-employed than older people (Blanchflower et al. 2001; see Peters et al. 1999). The effect of education on latent entrepreneurship is not clear cut, as Blanchflower et al. (2001)) and Grilo and Irigoyen (2006) empirically showed. Another determinant, which actually bridges the individual and regional level, is the entrepreneurial network of people. People from entrepreneurial families or with close friends who own businesses, are more likely to develop entrepreneurial values themselves (Davidsson and Honig 2003). An entrepreneurial environment, however, may also reflect favourable regional opportunities for new firm formation. At the regional level, in societies characterized by traditional entrepreneurial structures, like many small retail businesses and habitual entrepreneurship, personal attitudes towards firms and entrepreneurship are more positive than in regions dominated by a managerial culture (Weber 1904). ${ }^{3}$ Also the level of in-migration influences entrepreneurial attitude, as in general migrants are risk-takers, compared with other people (Saxenian 1999; Kirchhoff et al. 2002; Levie 2007). Furthermore, from the booming literature on the creative class, it can be derived that cities are the centres of diversity, creativity and new ideas (Lee et al. 2004; Koster 2007). Added to the positive effect of urban economic opportunities on new firm creation and development, especially in services (Audretsch and Keilbach 2004), it can be argued that urban areas attract and house people with a more positive attitude towards change, action and presumably also entrepreneurship. However, following Inglehart (2003) in his work on the relation between culture and economic development, it can be argued that regions with persistent high economic growth are also characterized by relatively positive attitudes towards entrepreneurship (see also Uhlaner and Thurik 2007). On the one hand, the pull-factor of economic growth, especially within the region, leading to high spending and growing markets in close vicinity, may well evoke entrepreneurial attitudes. On the other hand, (national) unemployment may push people into entrepreneurship. Finally, relating to institutional (formal and informal) effects, persistent market regimes and risk aversion attitudes may affect the prevalence of entrepreneurial attitudes at the regional level (Douglas and Shepherd 2002; Acs et al. 2007). Other determinants are obstacles like time-consuming startup procedures, lack of financial resources or administrative complexity, which may negatively influence entrepreneurial spirits. This is partly confirmed by Grilo and Irigoyen (2006), who found empirical evidence of a negative effect of perception of administrative complexity on latent entrepreneurship.

\footnotetext{
3 According to Etzioni (1987), the key word here is legitimation: the set of public values and morals which make entrepreneurship acceptable.
} 
2.2 Evidence on regional variation in entrepreneurial activity and its explanations

Entrepreneurial attitudes and entrepreneurial activity are closely related, but there are forces in between (Grilo and Irigoyen 2006). Linking entrepreneurial attitudes to entrepreneurial activity at the individual level, without using a longitudinal approach (i.e. allowing for time lags between attitudes and activity), leads to obvious results: people who are involved in entrepreneurial activity are bound to exhibit positive attitudes to entrepreneurial activity, and people who lack positive attitudes are almost certain not to be involved in entrepreneurial activity. At the regional level, a positive relationship between entrepreneurial attitudes and entrepreneurial activity is also expected-but less obvious. Ceteris paribus, one would expect that region A exhibiting substantially higher levels of entrepreneurial attitudes than region B to also reveal higher levels of entrepreneurial activity. However, there could be regional and national forces at play that hinder (or reinforce) a smooth "translation" of entrepreneurial attitudes to entrepreneurial activity. For example, if region A is characterized by an abundance of good job opportunities, or a high degree of social security, thus increasing the opportunity costs of entrepreneurship for individuals, the observed entrepreneurial activity may be lower than what could be expected from observed entrepreneurial attitudes. Below, we set out which kinds of regional and national forces could have an impact on entrepreneurial activity, on top of those that affect entrepreneurial attitudes. The latter forces have already been dealt with above.

\subsubsection{Early stage entrepreneurship}

As starting a firm is an individual decision, individual characteristics are important determinants of new firm formation (Sternberg and Wagner 2005; Bosma and Schutjens 2007). As a consequence, according to the labor-market approach to firm formation (Koster 2007), age structure, gender and education structure of the population play a role in explaining firm formation rates (Delmar and Davidsson 2000). In their study on the effects of social capital on new firms, Liao and Welsh (2003) stressed that social capital "..can be a substitute for other resources.." (p.152). A relatively recent but popular contribution to this view is the work of Florida (Lee et al. 2004), pointing to the positive effect of a creative class on entrepreneurship and especially new firm formation.

With respect to 'genuine' regional attributes, overviews in three special issues of Regional Studies (1984, 1994 and 2004), focusing on explaining regional firm formation), showed an abundance of empirical studies the past 20 years. Within countries, mainly regional determinants as purchasing power, urbanization and agglomeration effects, unemployment rates and the institutional framework are used to explain regional firm formation rates (Bosma and Schutjens 2007). Originally based on the urban incubator hypothesis, the large market potential in terms of both customers and suppliers and high knowledge intensity are important benefits for potential entrepreneurs (Tödtling and Wanzenböck 2003). With respect to agglomeration economies, the current debate is whether the presence of similar types of firms or different firm types stimulates new firm formation (localization and urbanization effects respectively) (Fotopoulos and Louri 2000; Rocha and Sternberg 2005). Also unemployment 
rates may affect start-up rates, in the sense that for the unemployed opportunity costs of self-employment are relatively low. Market conditions both at the national and regional level influence entrepreneurial activity. According to classical industrial economics market entry and exit arise from the confrontation of demand and supply. The carrying capacity of the market decides whether there is room left for new firms. The industry structure involved plays an important role here. On the supply side, market concentration (Tödtling and Wanzenböck 2003), the share of small- and medium-sized firms (Fritsch 1992), and entry- or exit barriers all affect entrance of new firms (Siegfried and Evans 1994). On the demand side, market potential and market growth, as well as GDP change, influence firm formation. Good market opportunities will trigger new entrepreneurs. As a result, exit and entry rates are highly correlated (Audretsch and Fritsch 2002; Bosma et al. 2010).

As regards informal institutions, Freytag and Thurik (2007) did not find a direct link between national culture and entrepreneurial activity, even though the relationship between national culture and entrepreneurial preference was significant. A possible explanation is the spatial level applied in their work. Attitudes to entrepreneurship may, as discussed above, differ within countries and therefore impact entrepreneurial activity at the regional level rather than at the national level. This leaves us to conclude that next to a more 'objective' measurement of regional output-levels or unemployment rates, a regional indicator comprising of (individual) attitudes toward entrepreneurship and business ownership, may contribute to our understanding of variations in entry rates. From the studies focusing on international differences in formal institutions related to entrepreneurship, the impact of national factors on entrepreneurial attitude and maybe even subsequently activity is striking. The World Bank report (2005) has revealed enormous national differences with respect to laws, regulations, and procedures in entrepreneurship registration. These regulatory obstacles may discourage entrepreneurial spirits. Therefore, national institutional forces (regulations, policy instruments) also affect entrepreneurial activity. With respect to entrepreneurship policy, large national differences exist - and have always existed, according to an extensive international comparison of policy in ten countries (Stevenson and Lundström 2001).

\subsubsection{Established business ownership}

With respect to demographic factors, the age-structure of the population is related to business ownership, as young people are underrepresented among business owners - they just lacked the time to set up and maintain a firm over 3.5 years. According to Schutjens and Wever (2000), whether firms survive and prove to be economically viable for over the first years, also depends on entrepreneurial and firm characteristics. With respect to regional economic attributes, to many firms the local or regional market is the most relevant production milieu (Malecki 1997). Therefore, regional levels of demand potential and industry (sectoral) composition (e.g. competition intensity) matter. These regional features also determine the extent to which new businesses are sustainable (see also Stuart and Sorenson 2003). Therefore, the debate on the importance of localization or urbanization economies is also relevant for established business ownership (Fotopoulos and Louri 2000), i.e. entrepreneurs whose firms 
survived the (often difficult) first years. Of course market growth increases the demand for goods and services and positively affects firm survival and thus the probability for an individual to go beyond the early stage with his or her company. But also limited competition and limited market concentration, combined with high exit barriers, contribute to high levels of established business ownership_-for example, in peripheral areas where business ownership is a traditional way of life and small businesses are often handed over within families.

At the national scale, both formal and informal institutions affect firm survival. The entrepreneurial climate or culture mirrors the regional c.q. national value attached to business ownership, risk-bearing behaviour and the status of being ones' own boss. It can be expected that the national variation in cultural entrepreneurial attitudes exceeds regional variation (Beugelsdijk and Noorderhaven 2004; Bosma and Schutjens 2009a).

\subsection{Linking attitudes to entrepreneurial activity}

Entrepreneurial attitudes at the regional level are determined by influences from different spatial angles. At the supra-national level, influences like risk-avoidance may play a role. Furthermore, there are values at the national and regional levels influencing regional entrepreneurial attitudes, of which the former level dominates. We also think that entrepreneurial attitudes are linked to entrepreneurial activities; however, this relationship is not clear-cut. The relationship is strengthened and/or 'distorted' by forces at the supra-national, national and regional level. Concerning entrepreneurial activity, we presuppose that as the decision to start a firm is a 'regional' (Feldman 2001) or even local event, regional forces will affect entrepreneurship in the process before start-up, leading to lower regional variation in the prevalence of Early Stage Entrepreneurial Activity (ESEA: nascent entrepreneurs or owners of young businesses up to 3.5 years old). Based on visual inspection of spatial differences in entrepreneurial activity (Bosma and Schutjens 2009a), we expect that national conditions matter more to established business ownership (EBO: Established Business Ownership with firms over 3.5 years old) than to early stage entrepreneurial activity (ESEA). This is illustrated in Table 1, depicting (by plusses) our expectations about the relative contribution and relevance of factors at different spatial levels on entrepreneurial attitudes and activity.

\section{Data and methods}

We use data from the Global Entrepreneurship Monitor (GEM) for creating indicators on regional entrepreneurial attitudes and regional entrepreneurial activity. Since 1999, GEM provides national indicators on entrepreneurial activity for an increasing number of countries (see Reynolds et al. 2005; Bosma et al. 2009a). The indicators are based on telephone surveys among the adult population. One important finding of the GEM studies so far is that cross-country variation in early-stage entrepreneurial activity is very persistent over the years. By merging the individual-level GEM data over 2001-2006, we create regional indicators on entrepreneurial activity and attitudes that pertain to the 2001-2006 period. We believe that merging 2001-2006 data is justified 
Table 1 Relative relevance of factors at three spatial levels on entrepreneurial attitudes and entrepreneurial activity

\begin{tabular}{|c|c|c|c|}
\hline & $\begin{array}{l}\text { Supra-national } \\
\text { differences }\end{array}$ & $\begin{array}{l}\text { Cross-country } \\
\text { differences }\end{array}$ & Interregional differences \\
\hline \multirow[t]{2}{*}{ Entrepreneurial attitude } & $\begin{array}{l}\text { - Market regime/legal } \\
\text { origin }\end{array}$ & $\begin{array}{l}\text { - National economic } \\
\text { growth indicators } \\
\text { (consumer trust etc.) } \\
\text { - Formal institutions } \\
\text { (regulation, legislation, } \\
\text { tax/welfare systems) }\end{array}$ & $\begin{array}{l}\text { - Network environment } \\
\text { - Population } \\
\text { composition } \\
\text { - Urban context } \\
\text { (population density) } \\
\text { - In-migration }\end{array}$ \\
\hline & ++ & ++ & + \\
\hline \multirow[t]{2}{*}{$\begin{array}{l}\text { Early Stage } \\
\text { Entrepreneurial } \\
\text { Activity (ESEA) }\end{array}$} & & $\begin{array}{l}\text { Entrepreneurial attitudes } \\
\text { (informal institutions) } \\
\text { - Formal institutions } \\
\text { (regulation, legislation) }\end{array}$ & $\begin{array}{l}\text { - Entrepreneurial } \\
\text { attitudes (informal } \\
\text { institutions) } \\
\text { - Urban context } \\
\text { (population density) } \\
\text { - In-migration } \\
\text { - Regional policy } \\
\text { programs } \\
\text { - Industry structure }\end{array}$ \\
\hline & & + & ++ \\
\hline $\begin{array}{l}\text { Established Business } \\
\text { Owners (EBO) }\end{array}$ & & $\begin{array}{l}\text { - Entrepreneurial } \\
\text { attitudes (informal } \\
\text { institutions) } \\
\text { - Formal institutions } \\
\text { (regulation, legislation) } \\
\end{array}$ & $\begin{array}{l}\text { - Entrepreneurial } \\
\text { attitudes (informal } \\
\text { institutions) } \\
\text { - Urban context } \\
\text { (population density) } \\
\text { - Regional policy } \\
\text { programs } \\
\text { - Industry structure }\end{array}$ \\
\hline & & ++ & + \\
\hline
\end{tabular}

++ high relevance of spatial level for explaining differences in attitudes/activity

+ some relevance of spatial level for explaining differences in attitudes/activity

since the existing evidence clearly points at the pervasiveness of regional differences in entrepreneurial attitudes and cultural values in general (Beugelsdijk et al. 2006). In addition, other regional measures of early-stage entrepreneurial activity seem to exhibit a large extent of path dependence (Parker 2005).

We use data from the Global Entrepreneurship Monitor (GEM) for creating indicators of regional entrepreneurial activity (dependent variables) and attitudes (independent variables). The selection of countries included in our study is restricted by data availability. First, we required GEM participation for at least 3 years in the 2001-2006 period. The result is indices on entrepreneurial activity and entrepreneurial perceptions over 125 larger regions in 18 countries and this is the classification that is shown in the maps in this paper. ${ }^{4}$ As regards the empirical investigation of the determinants of each

\footnotetext{
4 In this first selection we have indices for 125 regions corresponding to the classification used by ESRI. This classification consists of Nuts1 levels for Belgium, France, Germany, Greece, Ireland, the
} 
type of entrepreneurial activity we identified some densely populated regions situated within the previously identified larger regions; where the sample size permitted, we abstracted these dense regions and treated them as if they were separate from the larger regions of which they are part. An example is the Munich metropolitan area. This is situated in the Nuts1 region of Bavaria. However, based on the literature, we could expect patterns of entrepreneurial activity in the Munich area that are different from the rest of Bavaria. We therefore treated Munich, and the Bavarian region excluding Munich, as two separate regions in our empirical analysis. In short, this exercise led to an augmented sample of 147 regions. ${ }^{5}$ Owing to data availability for the independent variables and our restriction of a sample size of at least 700 valid cases per region for getting estimates with acceptable precision, we ended up with 127 observations over 17 countries in the regression analysis. ${ }^{6}$ All regional measures on entrepreneurial attitudes and activity were obtained by aggregating the individual level values irrespective of the year of observation. ${ }^{7}$ In this, each individual was assigned a weight. This weight equals the ratio between the expected share of the individual's gender and age group (based on Eurostat's regional database) and the share observed in the sample. For example, if in a particular region the number of males in the 18-24 age category are underrepresented in the sample (as compared with the statistics provided by Eurostat), these individuals have been given a weight higher than one, whereas other groups may have weights lower than one.

The regional indices provided in the paper are described in Table 2. The measures link directly to the presupposed interdependencies as set out earlier in Table 1. We have three distinct variables relating to entrepreneurial attitudes. ${ }^{8}$ Fear of failure relates to Hofstede's well-known risk-avoidance index, but in the GEM survey the question on which this measure is based specifically addresses risk avoidance to setting up a business. Differences have been analysed mainly on the supra-national and national nature as risk-taking propensity is closely related to the (national) social security system and institutional frameworks (Bosma et al. 2008). However, also within countries social

footnote 4 continued

Netherlands, and the United Kingdom. Nuts2 levels are applied for Croatia, Denmark, Finland, Hungary, Norway, Portugal, Slovenia, and Sweden and a combination of Nuts1 and Nuts2 for Italy, Spain, and Switzerland.

5 The abstracted regions are Antwerp and Ghent (Belgium); Aarhus (Denmark); Helsinki (Finland); Duisburg-Essen, Düsseldorf, Köln, Rhein-Main, Stuttgart and Munich (Germany); Budapest (Hungary); Dublin (Ireland); Amsterdam, Rotterdam, The Hague, and Utrecht (Netherlands); Barcelona, Valencia, Sevilla, and Malaga (Spain).

6 We are aware that delineating regions using a combination of Nuts1-3 administrative boundaries limits the possibilities to assess spatial variation in entrepreneurial attitude properly. Recognizing entrepreneurial opportunities often is even locally bounded, as many people rely on direct information on resources and customers from close-by contacts, family or friends (Feldman 2001; Sternberg 2009). However, lack of data prevents us from using more detailed spatial units.

7 Croatian regions had to be excluded from the analysis due to missing data for some of the independent variables.

8 It should be noted that the GEM questionnaire asks about perceptions related to attitudes, rather than about objective attitudes. Based on Davidsson (1991), also Minniti and Nardone (2007) and Bosma et al. (2008) have stated that perceptions are more relevant for assessing entrepreneurial possibilities than objective or 'real' attitudes. 


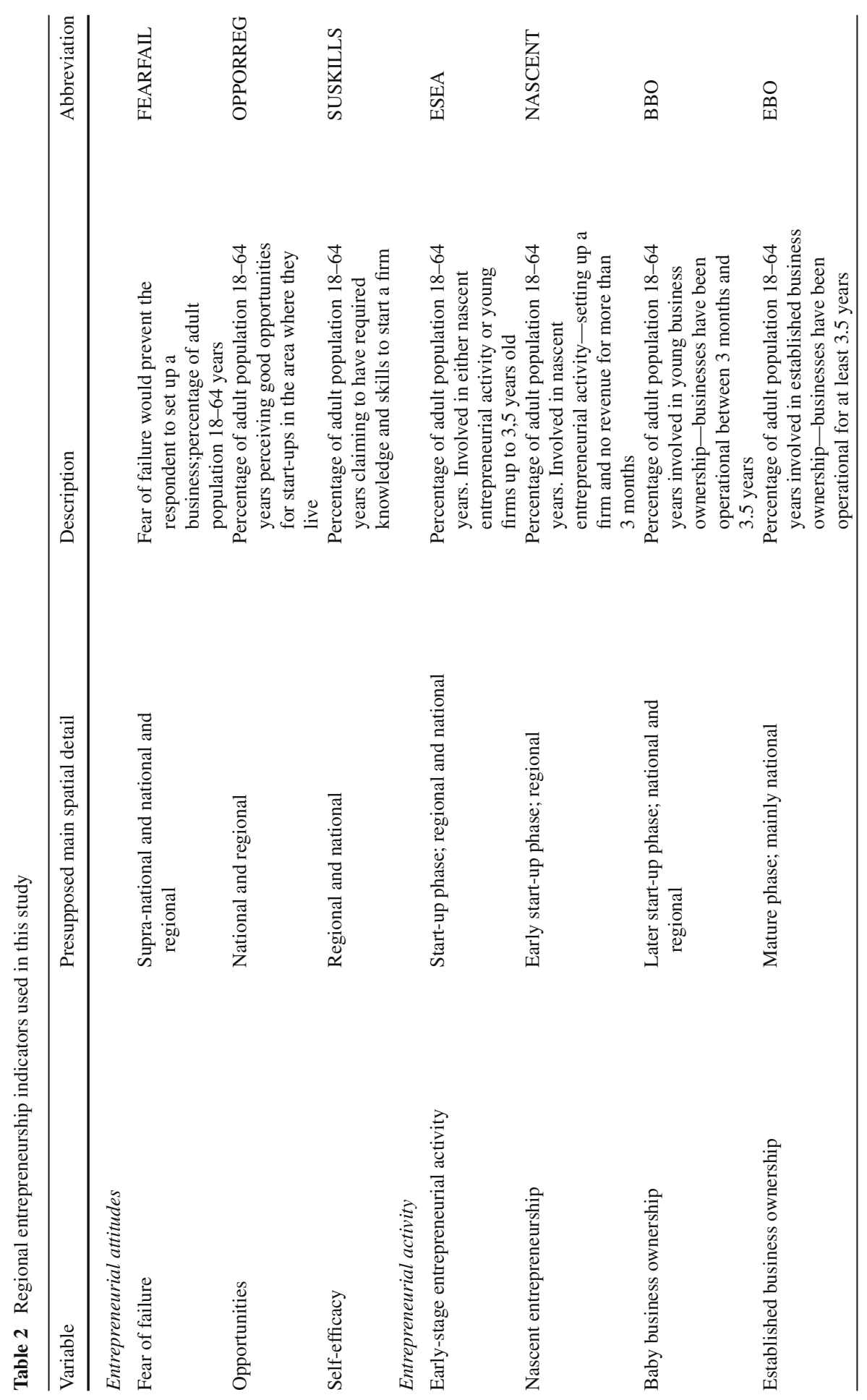


Table 3 Descriptive statistics for measures of entrepreneurial attitudes and entrepreneurial activity, for the 127 European regions included in the regressions

\begin{tabular}{|c|c|c|c|c|c|c|c|c|c|c|}
\hline & \multicolumn{2}{|c|}{$\begin{array}{l}\text { Basic } \\
\text { descriptives }\end{array}$} & \multicolumn{2}{|c|}{$\begin{array}{l}\text { Global spatial } \\
\text { autocorrelation }\end{array}$} & \multicolumn{6}{|c|}{$\begin{array}{l}\text { Correlation } \\
\text { table }\end{array}$} \\
\hline & Mean & SE & Moran's I & $\begin{array}{l}\text { I Getis and } \\
\text { Ord's G }\end{array}$ & 1. & 2. & 3. & 4. & 5. & 6. \\
\hline 1. FEARFAIL & 0.387 & 0.0793 & $0.83^{* *}$ & $0.029^{* *}$ & & & & & & \\
\hline 2. OPPORREG & 0.323 & 0.0111 & $0.74^{* *}$ & 0.027 & $-0.25^{* *}$ & & & & & \\
\hline 3. SUSKILLS & 0.411 & 0.0050 & $0.56^{* *}$ & $0.027^{*}$ & -0.03 & $0.22^{*}$ & & & & \\
\hline 4. ESEA & 0.054 & 0.0014 & $0.34^{* *}$ & 0.028 & 0.03 & $0.23^{* *}$ & $0.50^{* *}$ & & & \\
\hline 5. NASCENT & 0.031 & 0.0009 & $0.34^{* *}$ & 0.027 & -0.02 & 0.01 & $0.20^{*}$ & $0.82^{* *}$ & & \\
\hline 6. $\mathrm{BBO}$ & 0.026 & 0.0009 & $0.45^{* *}$ & $0.029^{*}$ & 0.08 & $0.35^{* *}$ & $0.61^{* *}$ & $0.83^{* *}$ & $0.38^{* *}$ & \\
\hline 7. $\mathrm{EBO}$ & 0.060 & 0.0016 & $0.49^{* *}$ & 0.027 & $0.19^{*}$ & $0.42^{* *}$ & $0.55^{* *}$ & $0.45^{* *}$ & 0.17 & $0.56^{* *}$ \\
\hline
\end{tabular}

NASCENT and BBO are the two components of ESEA (see Table 2)

*Significant at the 0.10 level (one-tailed for spatial autocorrelation; two-tailed for correlation table)

**Significant at the 0.05 level (one-tailed for spatial autocorrelation; two-tailed for correlation table)

acceptance of failure - and therefore fear of failure - may differ strongly, for instance, according to regional variation in traditional small-scale family business, religion or worker/wage-earner tradition. Perceived opportunities in the region are of course relevant at the regional level, but these perceptions are also bound to be linked to economic development and regulation at the national level. Our measure of self-efficacy is the assessment of individual capabilities, i.e. skills and knowledge, to set up a business. Perceived knowledge and skills to set up a business can be linked to human capital and demographics. Since these differ across regions, also within countries, this measure will not only show variation between countries but also across regions. Where some authors consider knowing entrepreneurs who started a business in the past 2 years as one of the factors capturing perceptions or attitudes to entrepreneurship (Minniti and Nardone 2007; Levie 2007), we postulate knowing other entrepreneurs is a network environment determinant for developing entrepreneurial attitudes (rather than an attitude itself) and-when pursuing these attitudes-for entrepreneurial activity. Assuming that many personal (and professional) networks are spatially bound, as was found among Dutch inhabitants (Mollenhorst et al. 2009) and young entrepreneurs (Stuart and Sorenson 2003), in a translation to the regional level we expect vibrant entrepreneurial regions to yield a milieu where entrepreneurial attitudes are easier developed and pursued into entrepreneurial activity.

Our two measures of entrepreneurial activity relate to different stages of entrepreneurship. Regional differences in entrepreneurial attitudes lead-ceteris paribus with respect to national and regional forces - to regional differences in the start-up phase: early-stage entrepreneurial activity. Before presenting the regression results on entrepreneurial attitudes and entrepreneurial activity, it is useful to examine their characteristics to see whether our presupposed relationships are confirmed by the data. Next to the means and standard deviations, spatial autocorrelations statistics and pairwise correlations are presented in Table 3. Two test statistics for establishing the degree of spatial autocorrelation have been presented. The Moran's I statistic is 
best-known and is able to detect both negative and positive spatial autocorrelation, but clustering of high or low values are not distinguished. The Getis and Ord statistic instead focuses on clustering of high and low values, but does not capture the presence of negative spatial correlation (see Getis and Ord 1992). Thus, both statistics can be used complementary. The Getis and Ord's G statistic requires a symmetric binary spatial weights matrix $W$. In our study we adopted a matrix of neighbouring regions, where each element $W_{i, j}$ equals one if regions $i$ and $j$ are adjacent and zero otherwise. This matrix was row-standardized for deriving the Moran's I statistics.

The results in Table 3 point at spatial autocorrelation in our dependent variables, although $p$ values differ between the two measures. For our purposes the Getis and Ord statistic seems to be of most importance, since potential concerns especially relate to clustering of high and low values, as will become clear from the maps shown in the next section. Nevertheless, these outcomes imply that we should check whether the residuals from our regressions suffer from spatial autocorrelation as well. In particular fear of failure and baby business ownership appear to exhibit spatial autocorrelation, as the test statistics are significant for both methods. For fear of failure, spatial autocorrelation is expected because this type of variable can be expected to exhibit supra-national patterns (see Bosma and Schutjens 2009a).

As regards entrepreneurial attitudes, we see that fear of failure is negatively correlated with perceived opportunities to start a business. The sign of this correlation coefficient makes sense; regions exhibiting higher risk-avoidance are also characterised by low levels of perceived opportunities to start a business. The self-efficacy variable, expected to provide differences on regional levels but also on the national level, is also correlated with perceived opportunities (but not with fear of failure). The two indicators for phases of entrepreneurial activity are positively correlated: in general, regions with high degrees of early-stage entrepreneurial activity also have high levels of business ownership. However, this is certainly not a clear-cut relationship as will be discussed further in this section. Early-stage entrepreneurial activity is strongly correlated with self-efficacy and weakly correlated with perceived opportunities. Looking at the two components of early-stage entrepreneurial activity, this is especially due to baby business ownership which is, like established business ownership activity, strongly correlated with both attitude measures. This provides initial evidence for the association between entrepreneurial attitudes and entrepreneurial activity at the regional level.

We include regional demography and labor market characteristics, supplied by the Eurostat Regional Database, Cambridge Econometrics database as regional-level explanatory variables. In addition, we include two national-level variables provided by the World Bank and OECD and the supra-national variable indicating legal origin from La Porta et al. (1999). In the regressions on both entrepreneurial attitude and activity we classify our independent variables into demographic effects, regional economic attributes, and institutional effects (Table 4). Thus, the demographic effects and regional economic attributes follow the same regional classification as the variables listed in Table 3, while the formal institutional effects vary only by country.

We are able to assess entrepreneurial attitudes at the regional level, which in our view is the level at which the individual assessment of risks, local opportunities and personal capabilities is acknowledged best. The formal institutional effects are 


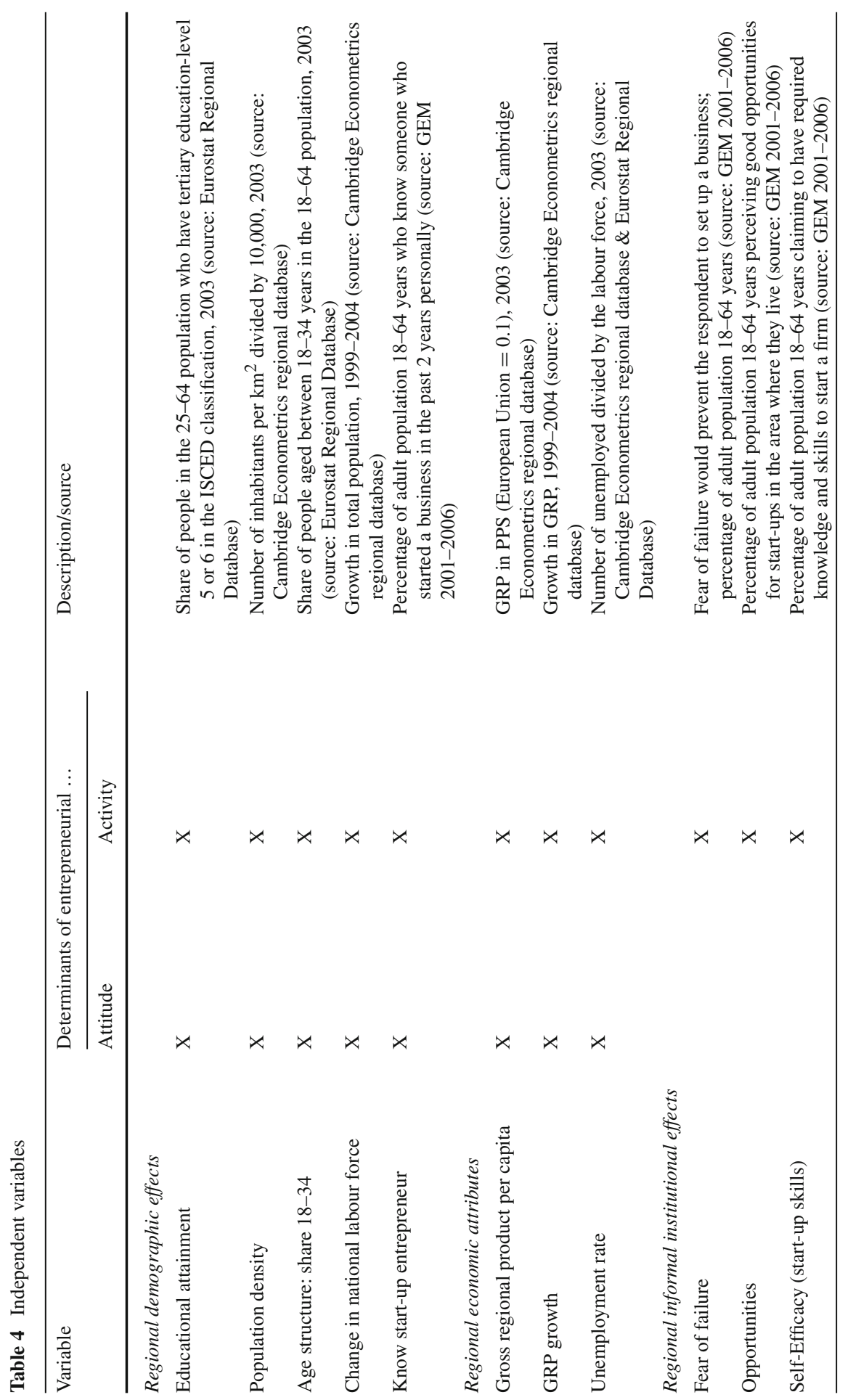




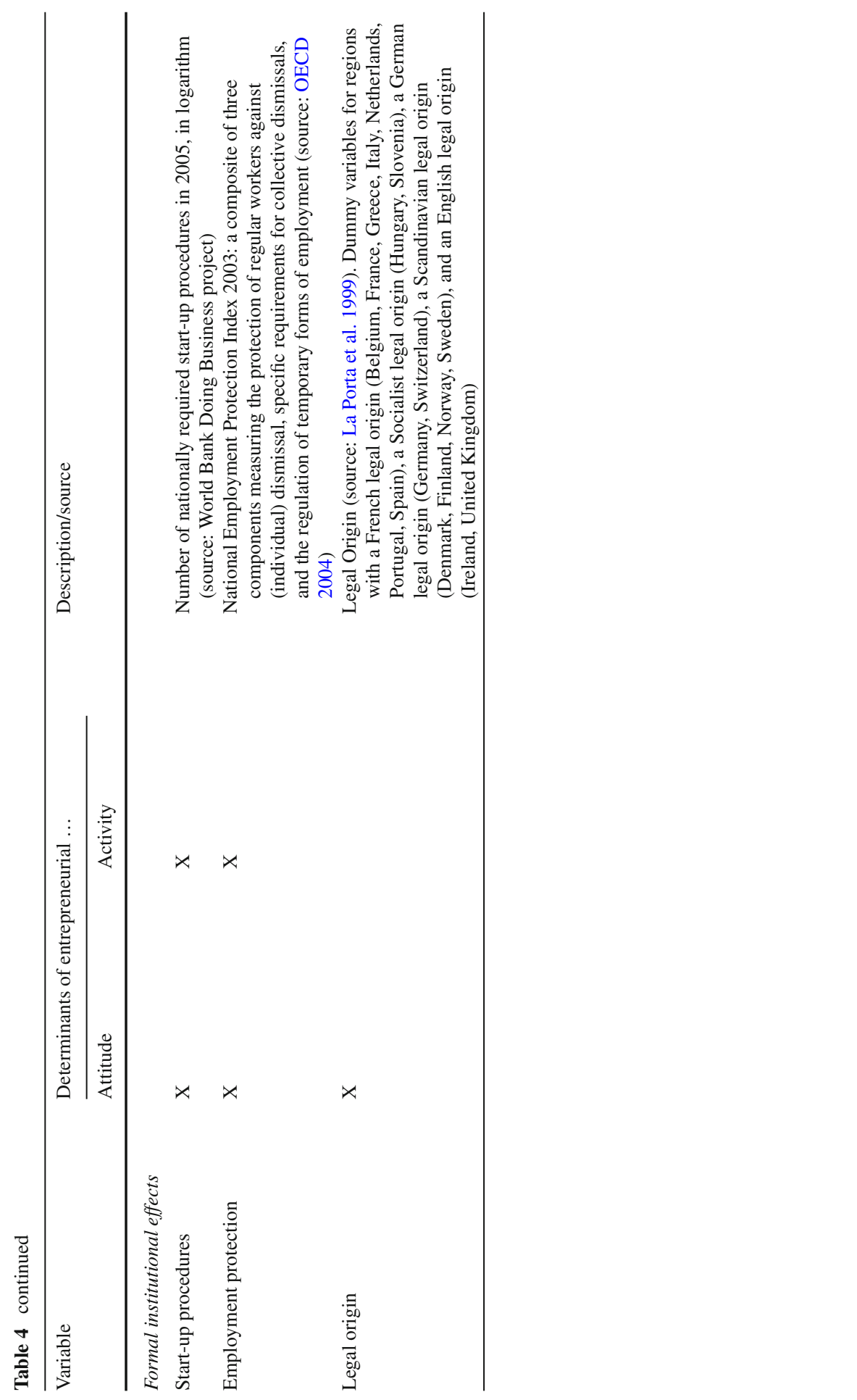


measured at the national level. All regressions are conducted using multilevel regression analysis, where the country identifies the second spatial level.

\section{Results: explaining entrepreneurial attitude}

Our three variables measuring entrepreneurial attitudes are presented in Figs. 1, 2 and 3. As regards cultural differences at the supra-national level, we see for instance that the French Mediterranean Region differs from the rest of France in Figs. 2 and 3 and resembles the entrepreneurial attitude patterns in Mediterranean regions in other South-European countries better. The North-Eastern part of France mirrors the German pattern in the figure on fear of failure (Fig. 1). Another group of countries with more positive attitudes is formed by the Netherlands, UK and Scandinavian countries. In Eastern Europe, perceived skills are fairly high, but perceived opportunities are rather low (Figs. 3 vs. 2). Germany and France both have negative attitudes to

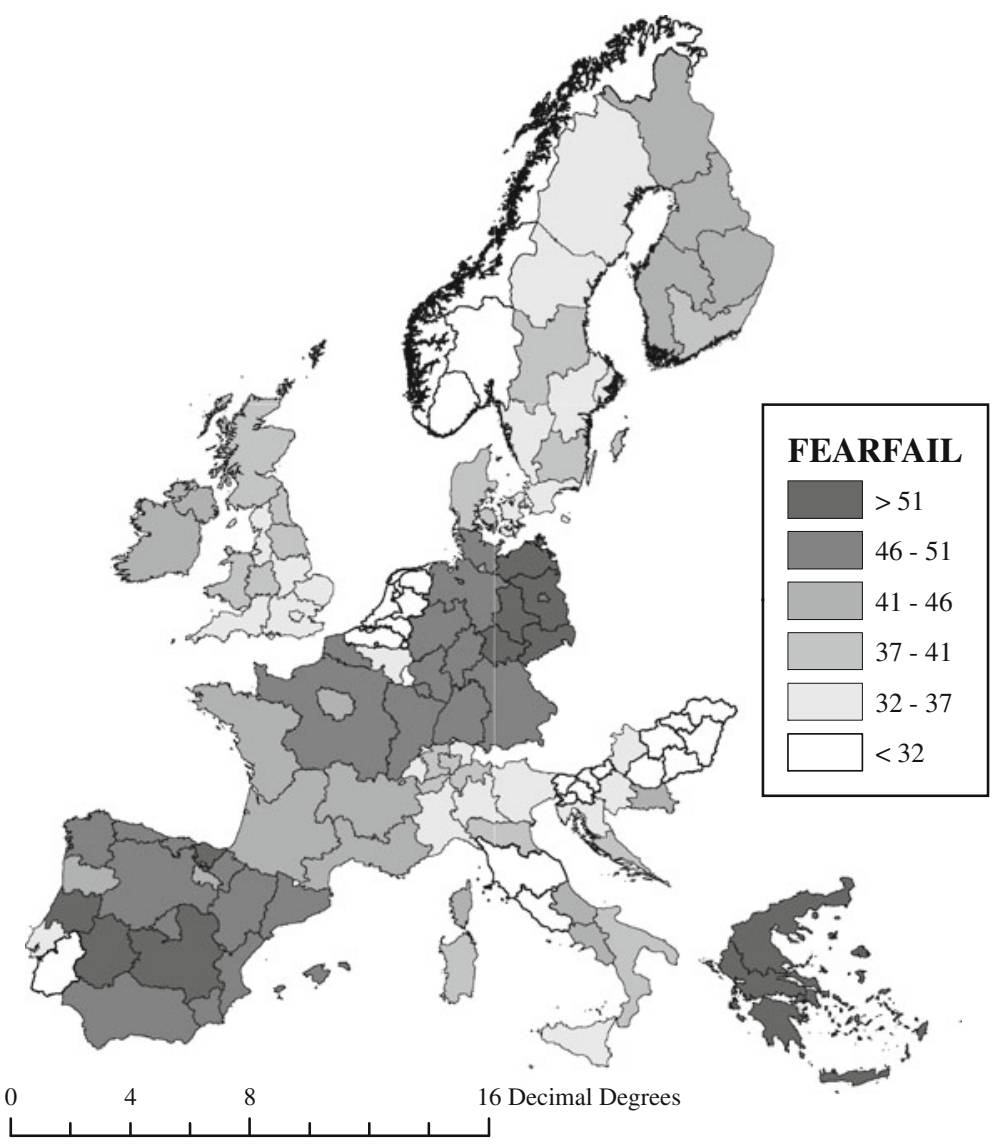

Fig. 1 "Fear of failure would prevent you from setting up a business", percentage of population between 18 and 64, 2001-2006. Data source: Global Entrepreneurship Monitor 


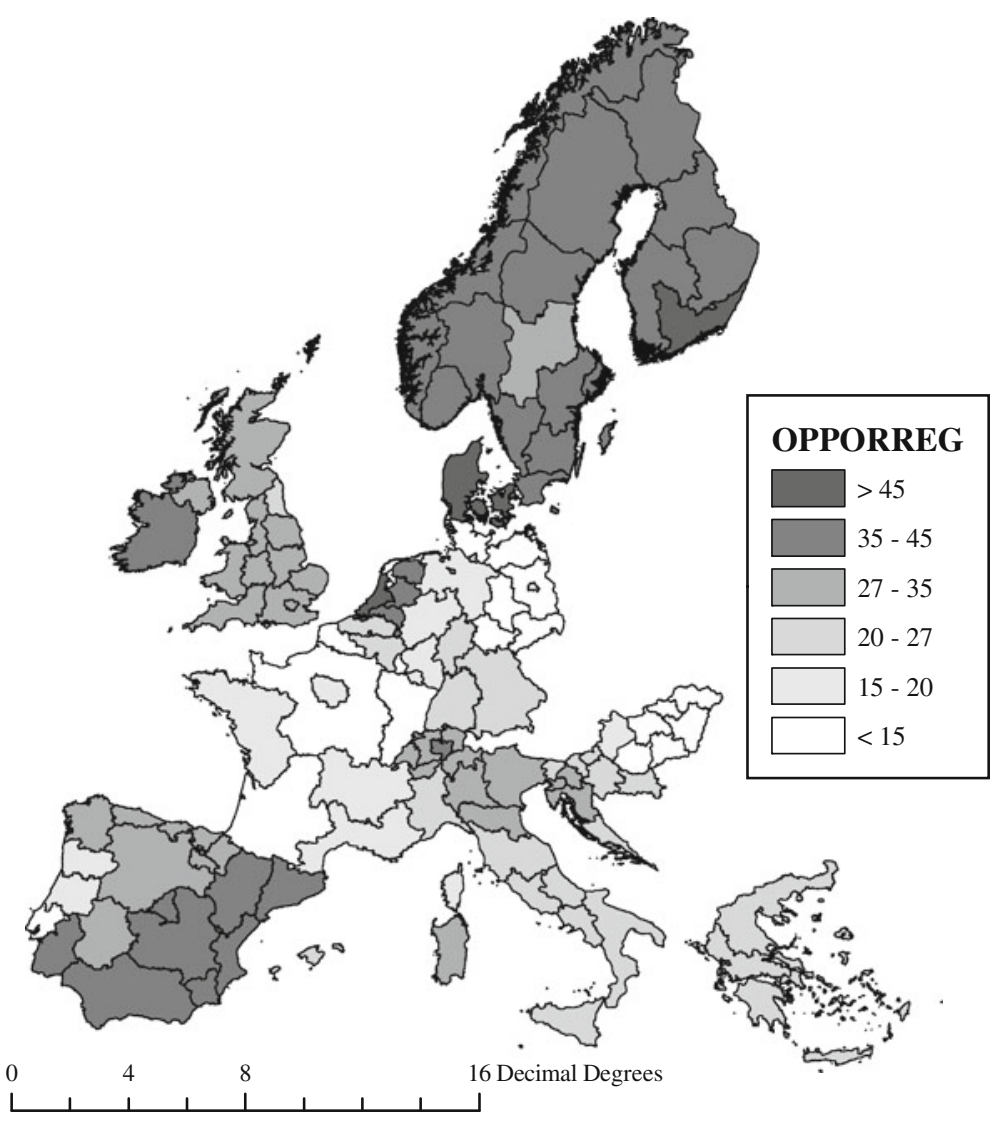

Fig. 2 "There are good opportunities to start a business in your area", percentage of population between 18 and 64, 2001-2006. Data source: Global Entrepreneurship Monitor

entrepreneurship. The fear of failure indicator is relatively low in Scandinavian countries, Great Britain, Belgium and the Netherlands and relatively high in the South of Europe (except for some regions in Italy). So, fear of failure seems to be a relevant measure identifying entrepreneurial culture beyond the national level. The three indicators exhibit different dimensions of entrepreneurial attitudes. Whereas, for instance, fear of failure is high in Spain and Greece, inhabitants in Spain are more positive as regards perceptions of good opportunities for starting a business than those in Greece.

Table 5 presents the results for our empirical analysis explaining entrepreneurial attitudes. It seems we were right to decompose into the three indicators at hand: fear of failure, perceived opportunity and perceived start-up skills and knowledge. The effects of demographic, economic and institutional variables on these three components vary in significance and sign. With the exception of the effect of regional unemployment rate, there is no factor influencing two or three components simultaneously.

High regional population density and population growth coincide with relative low fear of failure attitudes at the regional level. Surprisingly, it is not per se urban 


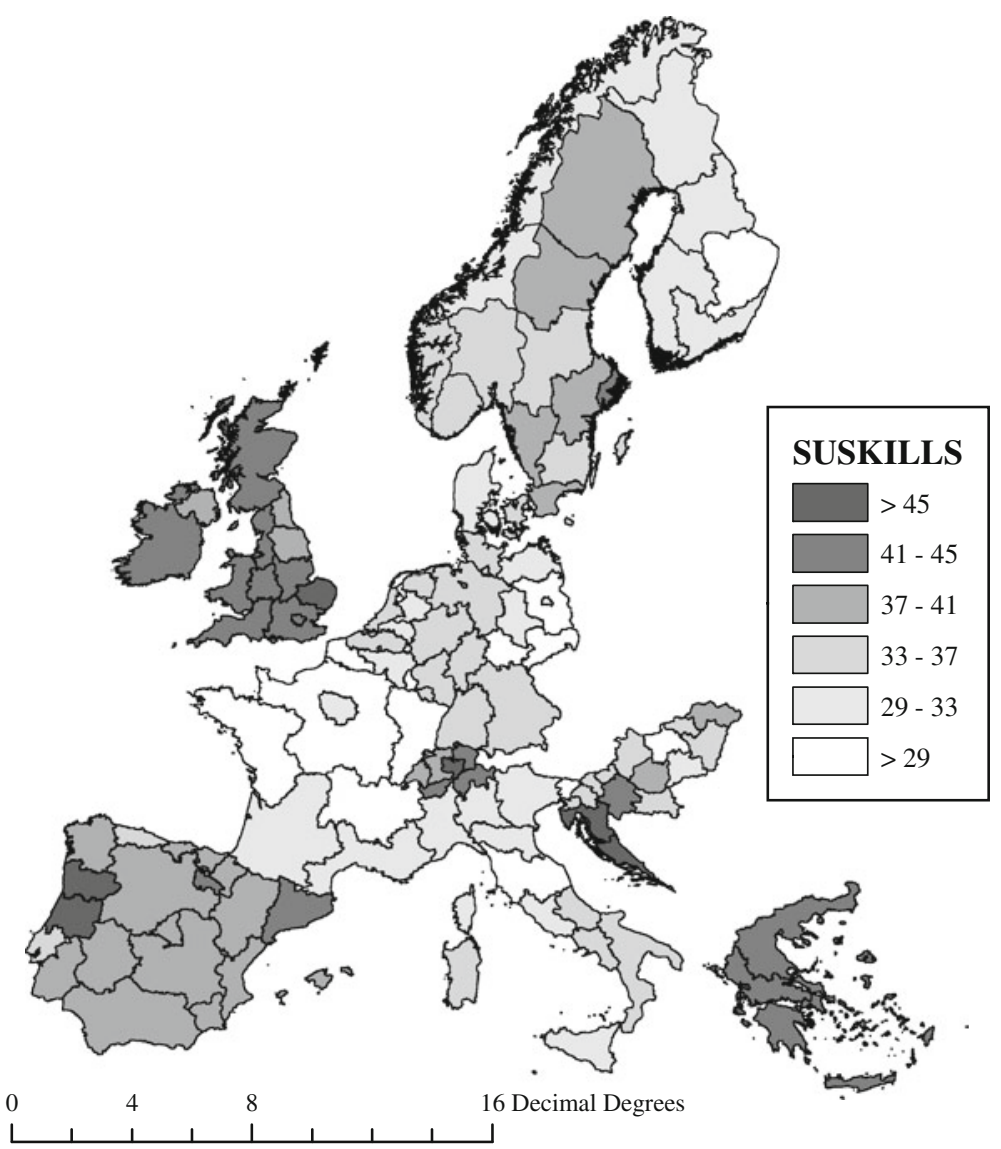

Fig. 3 "You have the required skills and knowledge to start business", percentage of population between 18 and 64, 2001-2006. Data source: Global Entrepreneurship Monitor

regions that are characterized by high rates of people perceiving economic opportunities or people mentioning having the skills and knowledge to start a firm, but regions where relatively many people know start-up entrepreneurs. ${ }^{9}$ Here, it seems that regional dynamics (measured in GRP growth and population growth) take over, as these indices are positively related to perceptions of business opportunities. It seems that urban regions house more risk taking people, while regional welfare functions as a pull-factor to personal perceptions of business opportunities. It can be argued that in urban regions showing high welfare growth rates, expressed by GRP, inhabitants will have more positive entrepreneurial attitudes than in other regions, which in turn and in time will again stimulate entrepreneurship, leading to new economic growth. An entrepreneurial network environment clearly contributes to this effect, causing people

\footnotetext{
9 If we exclude the variable 'Know start-up entrepreneur' for the regression explaining perceived opportunities and perceived skills and knowledge the results are very similar except for the share 18-34 (positive and significant at $p<0.05$ ).
} 
Table 5 Regression results: explaining regional entrepreneurial attitudes, 127 regions across 17 countries

\begin{tabular}{|c|c|c|c|}
\hline & Fear of failure & $\begin{array}{l}\text { Perceived } \\
\text { opportunities }\end{array}$ & $\begin{array}{l}\text { Perceived } \\
\text { skills and } \\
\text { knowledge }\end{array}$ \\
\hline \multicolumn{4}{|l|}{ Regional demographic effects } \\
\hline Educational attainment & $0.024(0.077)$ & $-0.010(0.113)$ & $-0.030(0.068)$ \\
\hline Population density & $-0.091(0.041)^{* *}$ & $0.078(0.061)$ & $0.017(0.037)$ \\
\hline Share $18-34$ age group & $0.126(0.134)$ & $0.278(0.198)$ & $0.143(0.120)$ \\
\hline Population growth & $-0.281(0.127)^{* *}$ & $0.376(0.186)^{* *}$ & $0.154(0.113)$ \\
\hline Know start-up entrepreneur & $-0.092(0.096)$ & $0.380(0.141)^{* * *}$ & $0.500(0.086)^{* * *}$ \\
\hline \multicolumn{4}{|l|}{ Regional economic attributes } \\
\hline GRP level & $0.052(0.056)$ & $-0.013(0.083)$ & $0.021(0.05)$ \\
\hline GRP growth & $-0.020(0.082)$ & $0.276(0.121)^{* *}$ & $0.006(0.073)$ \\
\hline Unemployment rate & $0.300(0.080)^{* * *}$ & $-0.485(0.118)^{* * *}$ & $-0.130(0.071)^{*}$ \\
\hline \multicolumn{4}{|l|}{ Formal institutional effects } \\
\hline Start-up procedures & $0.154(0.063)^{* *}$ & $0.087(0.089)$ & $0.047(0.056)$ \\
\hline Employment protection & $0.024(0.046)$ & $-0.081(0.065)$ & $-0.010(0.041)$ \\
\hline Legal origin "French" & $-0.079(0.083)$ & $0.059(0.117)$ & $-0.087(0.073)$ \\
\hline Legal origin "Socialist" & $-0.194(0.078)^{* *}$ & $-0.055(0.110)$ & $-0.058(0.069)$ \\
\hline Legal origin "German" & $-0.046(0.074)$ & $-0.019(0.105)$ & $-0.080(0.066)$ \\
\hline Legal origin "Scandinavian" & $0.014(0.088)$ & $0.266(0.125)^{* *}$ & $-0.107(0.078)$ \\
\hline Constant & $0.063(0.116)$ & $0.037(0.166)$ & $0.198(0.103)^{*}$ \\
\hline Log likelihood & 214.23 & 171.40 & 234.23 \\
\hline Wald Chi-squared & $60.04^{* * *}$ & $93.81^{* * *}$ & $62.96^{* * *}$ \\
\hline Variance country level (random effect) & $0.063(0.015)^{* * *}$ & $0.089(0.021)^{* * *}$ & $0.052(0.011)^{* * *}$ \\
\hline \multicolumn{4}{|l|}{ Spatial autocorrelation in residuals } \\
\hline Moran's I & $-0.151(0.073)^{* *}$ & $-0.003(0.073)$ & $0.080(0.073)$ \\
\hline Getis and Ord's G & $0.327(0.226)^{*}$ & $-0.091(0.227)$ & $-0.290(0.227)^{*}$ \\
\hline
\end{tabular}

$* p<0.1, * * p<0.05, * * * p<0.01$

The reference category for the legal origin variables is "English"

to think highly of their own entrepreneurial capabilities. As expected, high regional unemployment levels coincide with high regional fear of failure, but also with low rates of people perceiving both good business opportunities and to have relevant skills and knowledge to start a firm. In other words, at the regional level unemployment seems to lower entrepreneurial attitudes.

The formal institutional factors we included in our regressions appear to be less associated with entrepreneurial attitudes than expected. Controlled for other factors we only found a positive effect of a large number of start-up procedures on fear of failure, which is as expected. The finding that the amount of start-up procedures does not affect perceptions of people's own skills and knowledge for stating a business is also not surprising. It seems that whenever perceptions relate to the idea of actually going ahead with starting a business - which is the case for the question underlying fear of failure 
rates but not for perceived opportunities (opportunities may also be spotted for others) or for perceived skills and knowledge- high start-up barriers do matter. We also find countries with a socialist legal origin to reflect lower fear of failure, controlling for the other effects. Thus, fear of failure does not seem to be invoked by the socialist historical regime as such in these countries. In addition, fear of failure may be lower in areas where there are relatively limited economic alternatives. Inhabitants from Scandinavian countries see many relatively many opportunities for starting a business, also controlling for the effect of other determinants. Finally, the significant effects of the country level variance point at the relevance of using multilevel regressions.

The Moran's I and Gertis and Ord's G statistics point at some potential spatial heterogeneity problems in the regression. In particular, the model explaining fear of failure seems to exhibit spatial heterogeneity that is not accounted for by the multilevel (country) effects and the independent variables included in the model. We have, in auxiliary regressions, also included Hofstede's cultural dimensions. However, including these did not lead to significant changes in the Moran's I and Getis-Ord statistics. Running a spatial error regression model yielded an estimate of 0.23 for the spatial error coefficient $\lambda$ and did not result in considerable changes for the other estimates. ${ }^{10}$

\section{Results: explaining entrepreneurial activity}

Figure 4 sets out early-stage entrepreneurial activity (ESEA) rates per region. ESEA measures the percentage in the adult population who are either involved in a startup attempt or owner-manager of a young business. Our results clearly point at the importance of distinguishing regions for exploring early-stage entrepreneurial activity. We observe that for most countries this percentage is highest in dense areas such as London, Madrid, Catalunya (Barcelona), Bavaria (Munich), Copenhagen, Stockholm, Brussels, and the western part of the Netherlands (Amsterdam, Rotterdam and The Hague). This finding supports the existing evidence on the importance of urbanization for entrepreneurship (see e.g. Armington and Acs 2002). Next to population density there may also be other regional forces affecting regional levels of early-stage entrepreneurial activity. Since ESEA is a composite measure including both the pre-start-up phase (NASCENT) and the initial post-start-up phase (BBO) these measures have been presented in separate maps, in Figs. 5 and 6, respectively. These two maps point out that there are some similar patterns in regional prevalence for these two phases, but also some differences, especially in Southern Europe. Fig. 7 depicts the regional share of established business ownership (EBO), which resembles the regional pattern of baby business ownership (BBO) in Fig. 6 most.

A first analysis of determinants of entrepreneurial activity showed significant contributions of the three components of entrepreneurial attitude (results available on request). ${ }^{11}$ We started off with a model including demographic effects (age structure), regional economic attributes and national (formal) institutions (baseline

\footnotetext{
10 This spatial error regression model did not consider the multilevel effects as the ones shown in Table 5.

11 Additional analysis showed that adding composition variables (age structure), regional attributes and national (formal) institutions to a baseline model of only entrepreneurial attitude variables caused the parameters of the latter to change only minimally.
} 


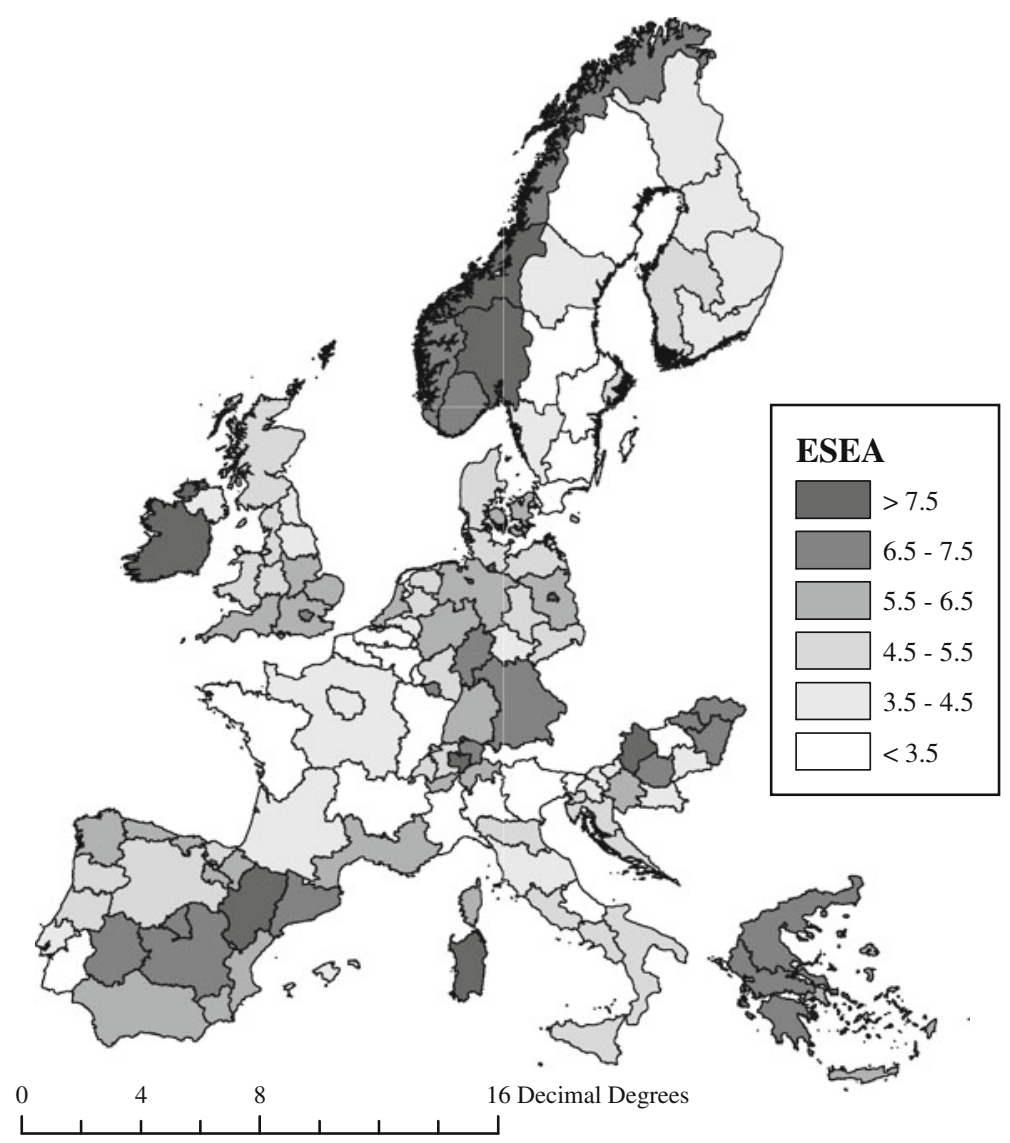

Fig. 4 Early-stage entrepreneurial activity (ESEA), percentage of population between 18 and 64, 2001-2006. Data source: Global Entrepreneurship Monitor

model) only. The parameters of these effects changed markedly when entrepreneurial attitudinal variables were included in the model. For instance, entrepreneurial attitudinal effects seem to fully capture the positive effect of knowing start-up entrepreneurs on ESEA rates; only for nascent entrepreneurship levels, the positive association with high regional rates of people knowing start-up entrepreneurs remains significant. The positive effect of high population density on ESEA is also persistent. ${ }^{12}$ Again, we find a significant effect of country level variance in all models.

Three general conclusions can be drawn from the models in Table 6. First, the role of entrepreneurial attitudes in explaining entrepreneurial activity at the regional level is confirmed. Two of the three attitudinal components measured both affect ESEA

\footnotetext{
12 The overriding effect of informal institutions and the persistent effect of population density were confirmed when we conducted auxiliary regressions based on the second model in Table 6 and excluding the formal institutional effects. Also here the population density was found to be positive and significant while the 'know-start-up entrepreneur' coefficient remained insignificant.
} 


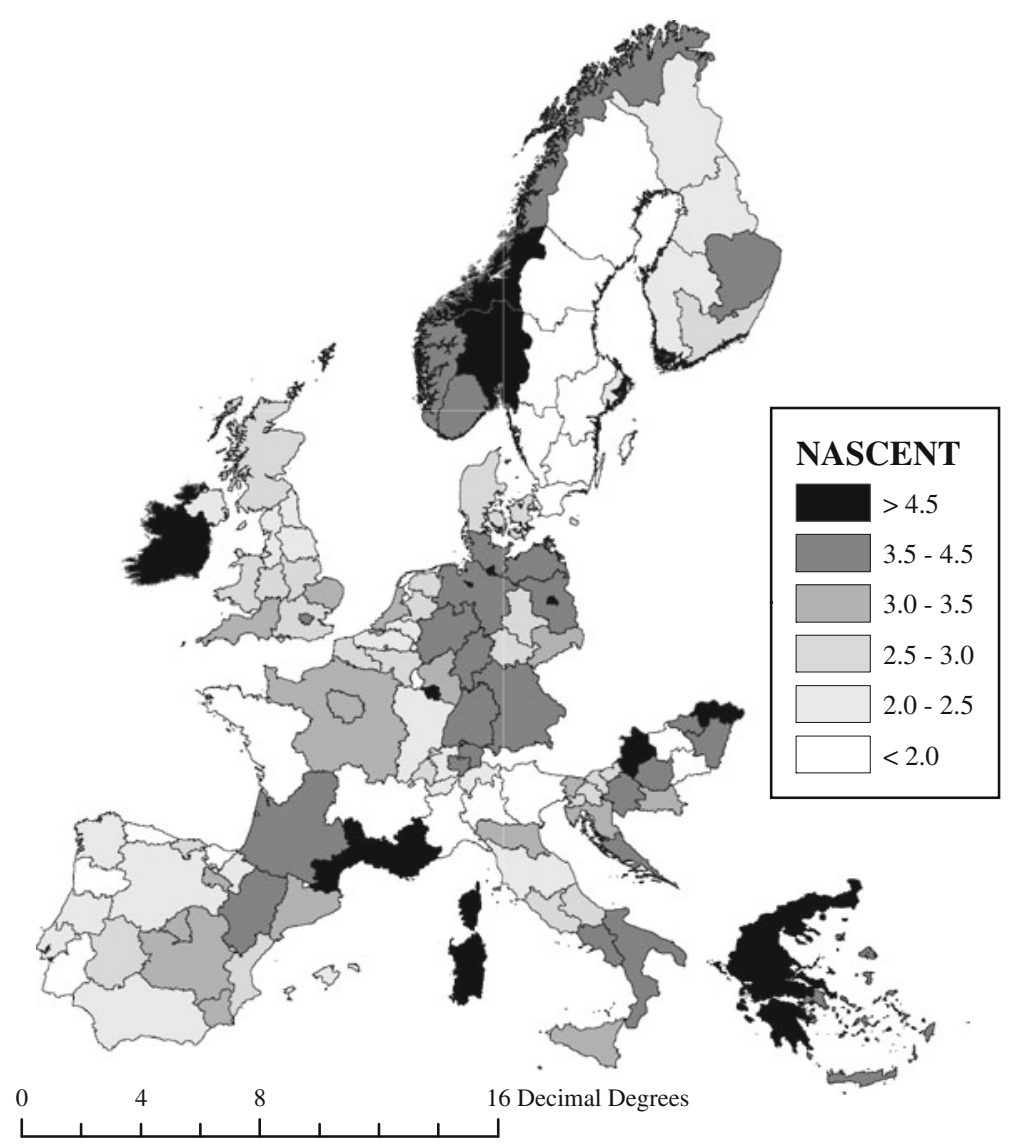

Fig. 5 Nascent entrepreneurial activity prevalence rate (\% in population between 18 and 64 years), 2001-2006. Data source: Global Entrepreneurship Monitor

and EBO. Our analysis shows that not only in the early start-up phase, when people are taking steps to set up a firm, but also in a later stage, the perception of opportunities and the assessment of start-up skills matter to entrepreneurship. Especially the latter strongly and positively influences established business ownership, suggesting that for stimulating both nascent entrepreneurship and actual start-up rates, positive individual perceptions on start-up skills and knowledge (or self-efficacy) should be increased. Furthermore, high regional shares of people perceiving start-up opportunities in the vicinity, may lead to high entrepreneurial activity rates. The insignificant effect of fear of failure on entrepreneurial activity (both ESEA and EBO) is striking. A second main finding is that regional shares of nascent entrepreneurship (NASCENT) have other explanations than regional shares of baby business ownership (BBO). It seems that explanations of ESEA closely resemble those of nascent entrepreneurship, ${ }^{13}$ but that the prevalence of young business ownership has distinct determinants,

\footnotetext{
13 It has to be taken into account, however, that regional NASCENT rates exceed regional BBO rates, causing the dominance of NASCENT in ESEA indicator.
} 


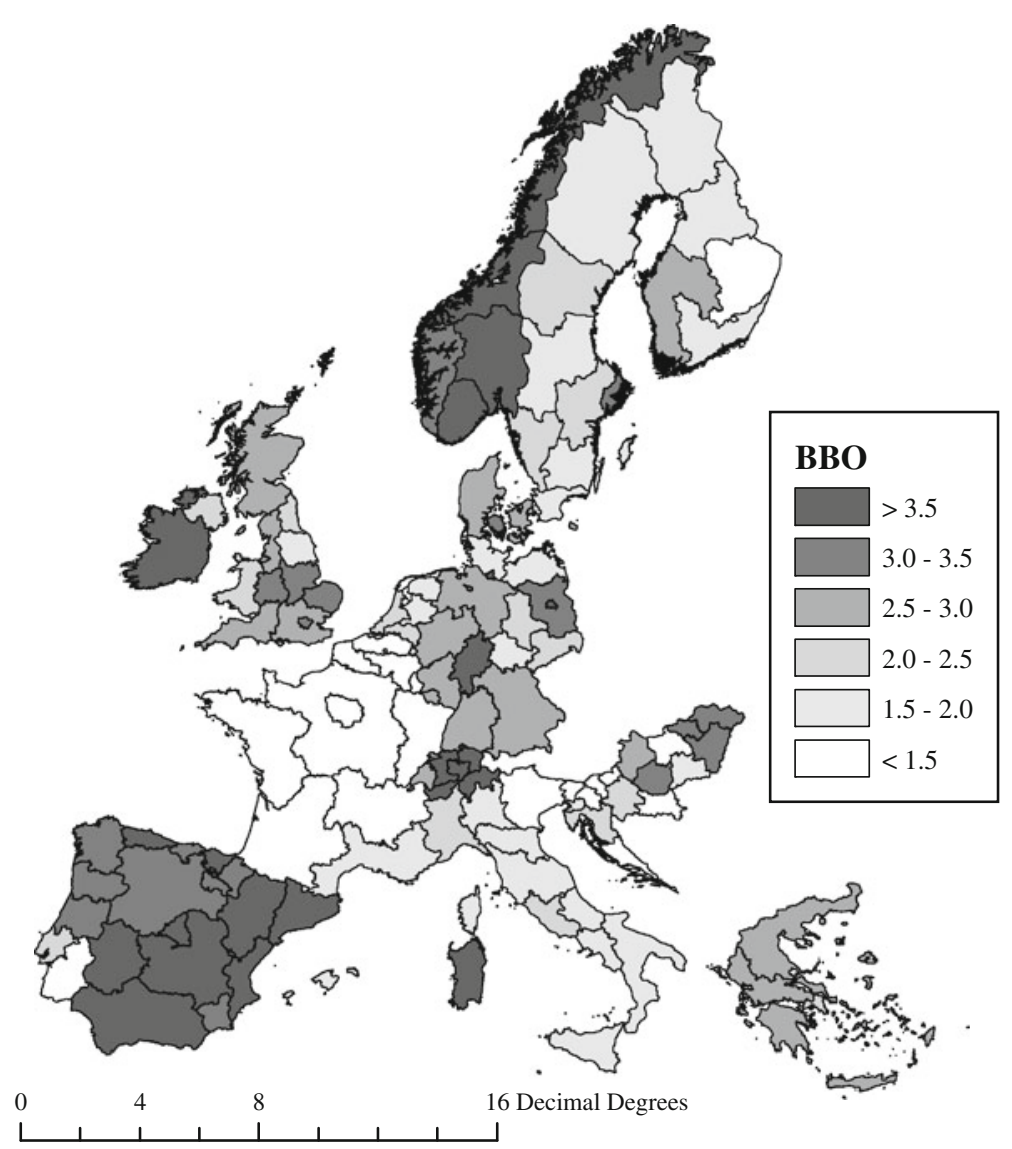

Fig. 6 Baby business ownership prevalence rate (\% in population between 18 and 64 years), 2001-2006. Data source: Global Entrepreneurship Monitor

even though both phases are positively correlated (see Table 3). A third main conclusion is that regional economic attributes do not relate to entrepreneurial activity at all. While this result may be counter intuitive, we would like to point out that our analysis only focuses on different stages of entrepreneurial activity and not on specific types of entrepreneurship. For example, Bosma and Schutjens (2009b) found that for high-growth-oriented ESEA, regional welfare levels do matter (a positive U-shaped effect of GRP).

A closer look reveals that, quite unexpectedly, regional age composition is not related to NASCENT, but only to EBO. This means that entrepreneurial attitudes effect on NASCENT is more important than the age effect, suggesting an interaction between entrepreneurial spirits and age. Again, analyses of specific types of entrepreneurship show that young regional age composition does stimulate high-growth entrepreneurial orientation (Bosma and Schutjens 2009b). High regional shares of 18-34 aged people strongly and negatively correlate to EBO rates, meaning that regions with young populations count relatively less established business owners. This may be due to the logical fact that — at the individual level—setting up and running a business takes time and 


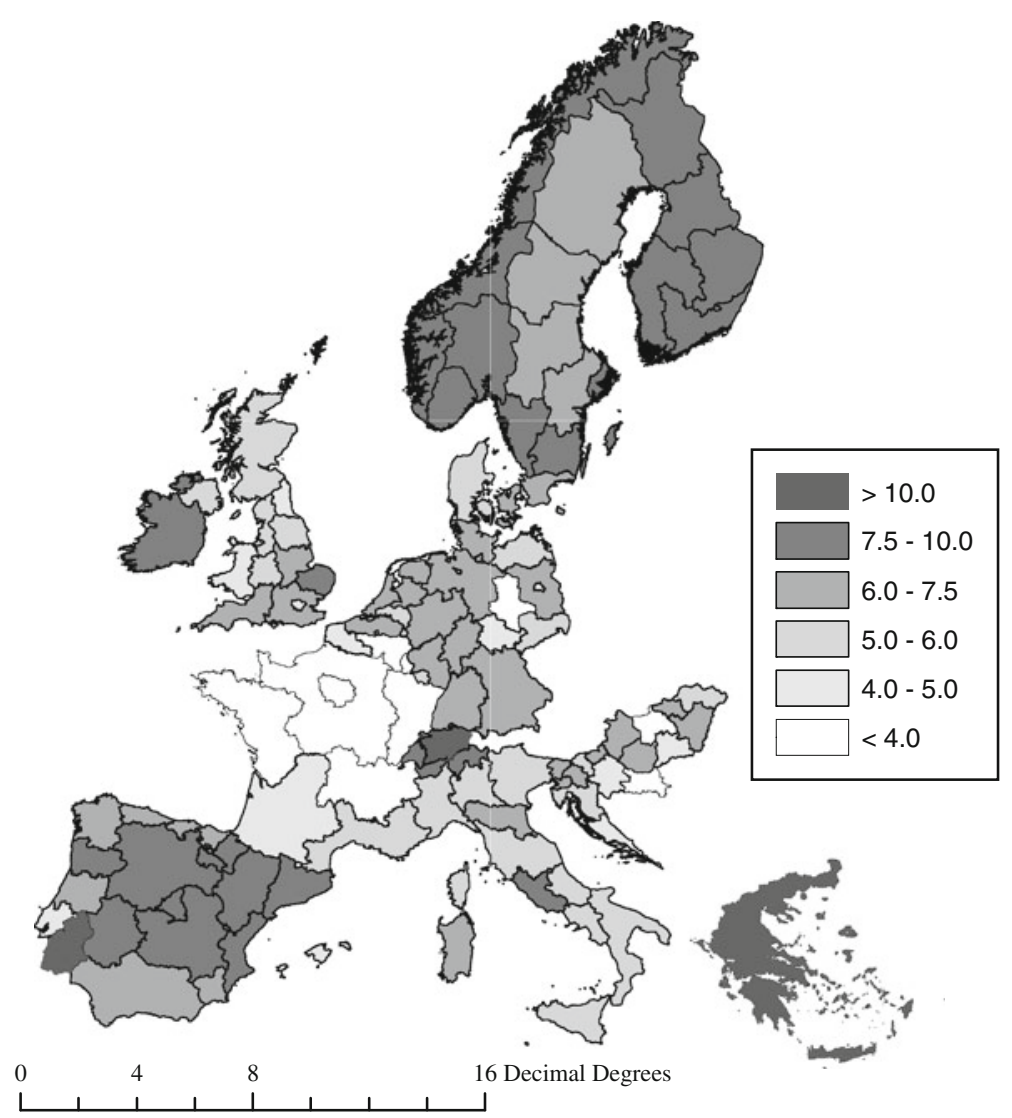

Fig. 7 Established business ownership rates percentage of population between 18 and 64, 2001-2006. Data source: Global Entrepreneurship Monitor

therefore comes with age. As our maps already suggested, urban regions, indicated by high population density, are characterized by many nascent entrepreneurs per inhabitant; indeed the vibrant incubators of new firms. Again, an entrepreneurial climate may add to this, as regions characterized by young entrepreneurship clearly have relative high shares of people taking the first steps to set up a business (NASCENT).

When informal institutional effects (at the regional level) are included, national (formal institutional) variables do no longer influence early-stage entrepreneurial activity. Countries with a large number of start-up procedures do not have lower ESEA rates than other countries. This means that the number of national start-up regulations does not discourage nascent entrepreneurship - in contrast with the findings of Van Stel et al. (2007), who perform an empirical analysis on a larger and more heterogeneous set of countries (but do not consider the regional dimension) - but does hamper actually owning a firm. An unexpected finding is the positive influence of the interaction effect of FEARFAIL and the number of start-up procedures on EBO. While the main effects of FEARFAIL and start-up burdens have the expected signs, in regions facing many national start-up regulations and high fear of failure rates, the share of established 


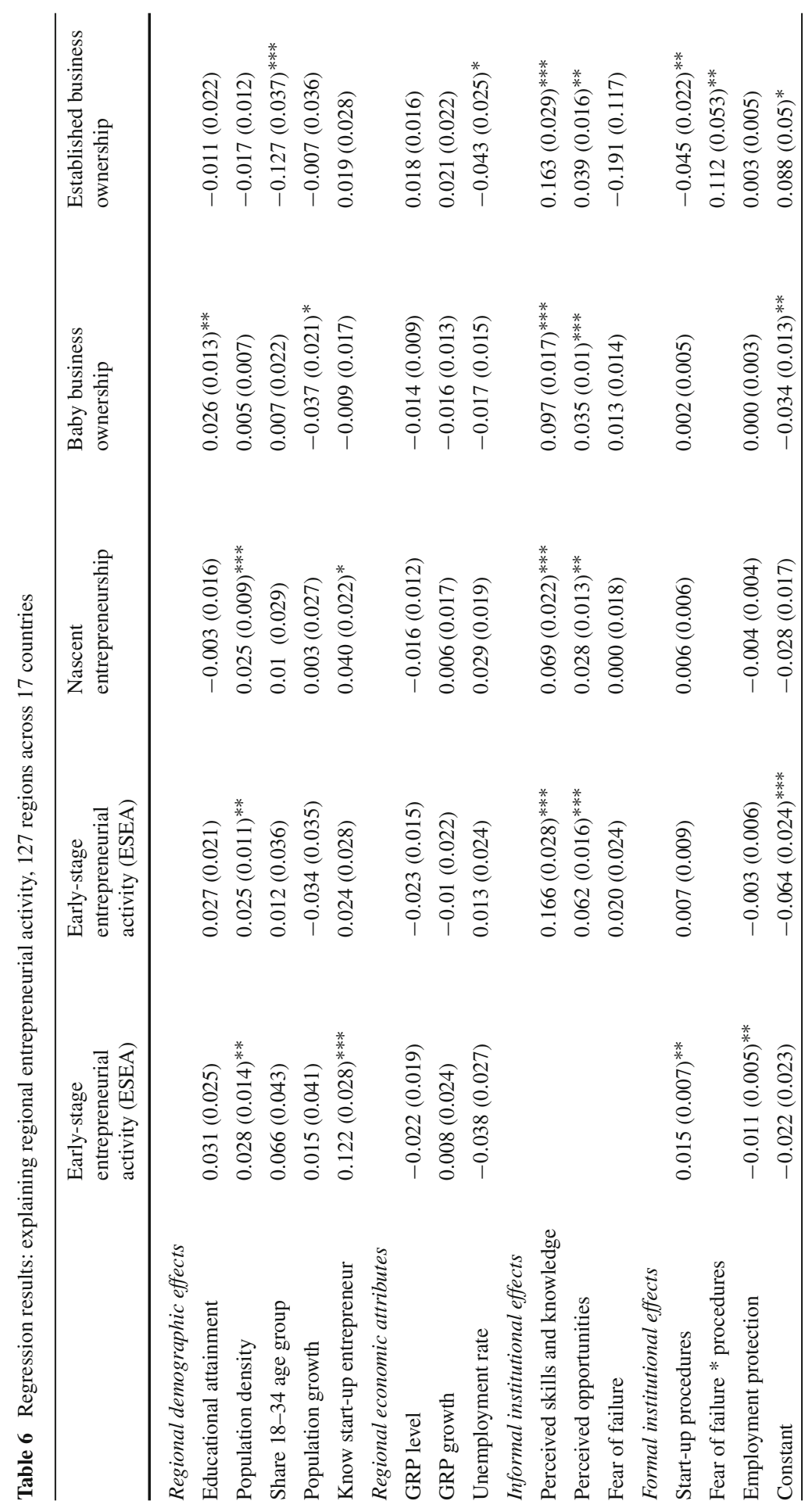




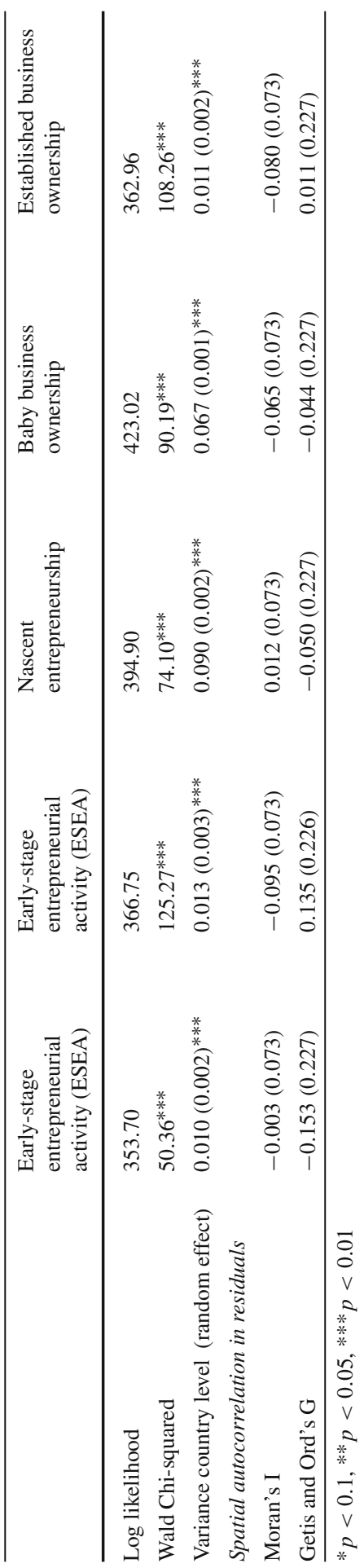


businesses is high. A possible explanation may be that the fear of failure measure is related to starting a business and thus reflects more a reluctance to business dynamics as opposed to the more static number of established firms in the presence of substantial amounts of start-up procedures. However, this has to be analysed more thoroughly. The Moran's I and Getis-Ord statistics do not point at potential spatial heterogeneity problems in our models explaining various stages of entrepreneurial activity.

\section{Conclusion and discussion}

Urban regions showing high GRP growth, low unemployment rates and vibrant entrepreneurial regions where people come across other start-up entrepreneurs yield a milieu where entrepreneurial attitudes are easier developed than elsewhere. We have learned that these entrepreneurial attitudes have a specific effect on entrepreneurial activity, even taking other national and regional factors into account. Decomposing entrepreneurial attitude into three dimensions and distinguishing between phases in early-stage entrepreneurial activity (ESEA) proved relevant for our explanatory analyses. This means that understanding entrepreneurial behaviour and attitudes, and eventually influencing entrepreneurship in general, calls for different instruments at different spatial scales in different stages of entrepreneurship. At any case, this calls for caution in using entrepreneurial attitudes and activity as a 'black box'.

Based on the literature, we expected formal national institutions to affect entrepreneurial activity, but our analyses showed that-when we control for the effect of informal institutions at the regional level—this only holds for EBO. For early-stage entrepreneurship (NASCENT and BBO) informal institutions are more important; in particular two indicators of entrepreneurial attitudes at the regional level (perceived opportunities and skills and knowledge). In turn, these two indicators are influenced by regional economic attributes (population growth, the degree to which people know other start-up entrepreneurs, GRP growth and unemployment rates). The fear of failure indicator, however, significantly correlates with population density (negative association) and unemployment rate (positive relation). Recently it has been shown that formal institutions affect the type of early stage entrepreneurship in terms of both growth and innovation orientation (Bosma et al. 2009b).

As we have shown, the positive relation between strong entrepreneurial attitudes and subsequent entrepreneurial activity is not straightforward. There are national formal institutional and regional forces at play, which at the individual level reinforce or deter the decision to indeed start a business. Translating this issue to the regional level, we can map this mismatch between entrepreneurial spirits and entrepreneurial behaviour using the Untapped Entrepreneurial Potential index (UEP). The UEP index relates to people who think they have the skills, see good opportunities for start-ups in their region, but are not involved in entrepreneurship. ${ }^{14}$ In Fig. 8 it is shown that especially in Sweden and Ireland the share of people with entrepreneurial attitudes

\footnotetext{
14 A word of caution here: a high UEP rate does not necessarily imply that the regional share of entrepreneurial activity is low; it only means that the regional rate of people with entrepreneurial attitudes is far exceeding the regional rate of people involved in entrepreneurial activity. Ireland for instance, shows high UEP, but also shows high ESEA rates.
} 


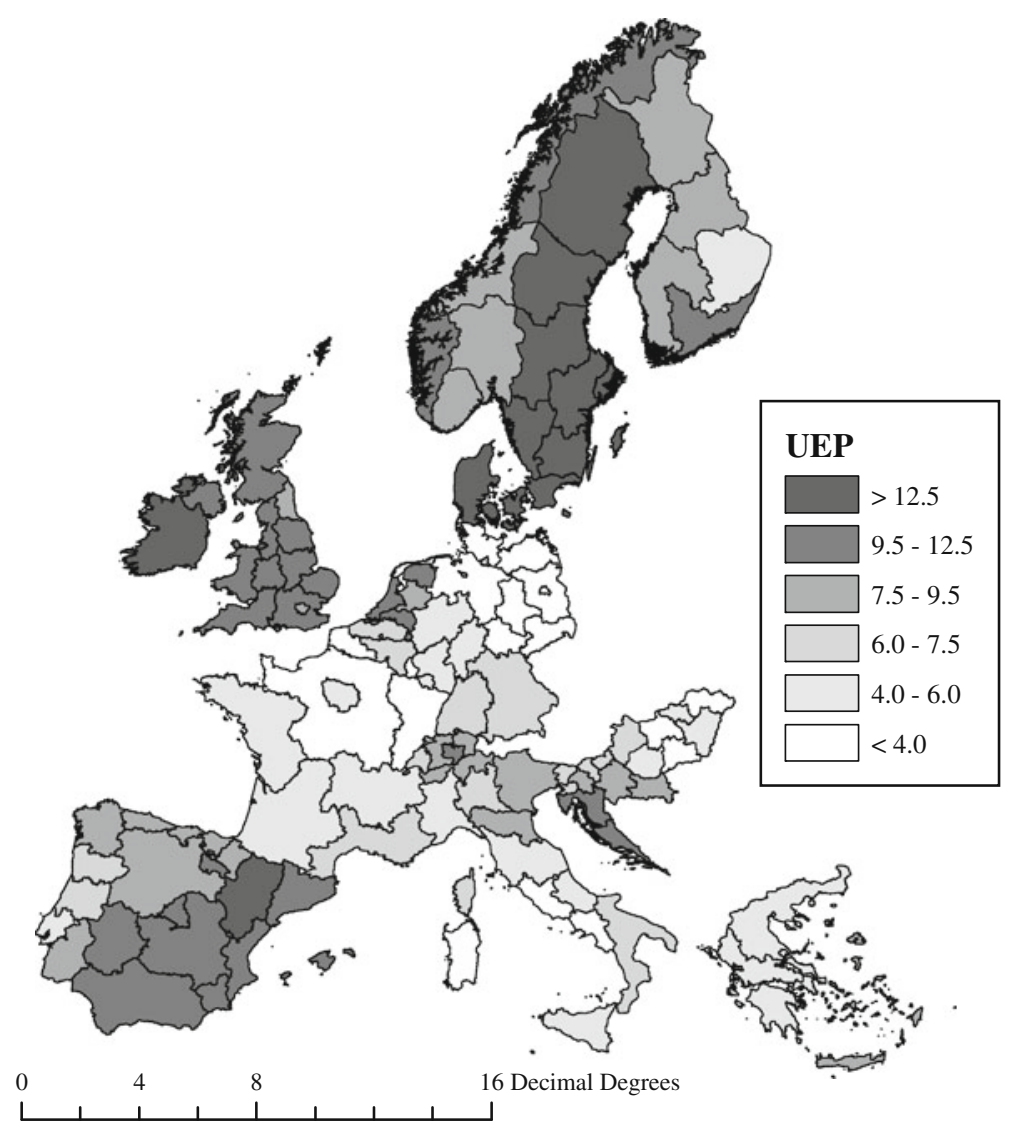

Fig. 8 Untapped entrepreneurial potential: claims to have skills for setting up a business, perceives good opportunities but not involved in entrepreneurship. \% of population between 18 and 64, 2001-2006. Data source: Global Entrepreneurship Monitor

far exceeds the share of people realizing their entrepreneurial ambitions, while in all North-East German regions and Northern France, this difference is only small. Based on the national differences in regional variation of the UEP, it is also clear that for some countries national forces (for instance the existence or lack of institutional barriers) dominate (viz. Sweden, Ireland, The Netherlands, Belgium, Portugal, and to a lesser extent France), while in other countries regional forces prevail (viz. Italy, Hungary, Norway, Germany, UK and Spain). Although in this paper we do not analyse the determinants of UEP directly - as its calculation would involve both entrepreneurial attitude and activity which makes an interpretation rather complex - this finding is highly relevant for policy makers. In our opinion, its relevance lies in the opportunity to develop and reinforce tailor-made instruments at various spatial levels to stimulate regional entrepreneurship activity.

We realize that our study has its limitations. In future research on explaining entrepreneurial activity we have to tackle the methodological problem of distinguishing the effect of entrepreneurial attitudes from other determinants, as the latter also influence 
entrepreneurial attitudes. Within the multilevel regression analyses shown this problem is circumvented, but not yet solved entirely, as it is still unclear to what extent the effect of entrepreneurial attitudes on entrepreneurial activity in fact captures effects of other regional or institutional variables. In addition, the time dimension is absent in our paper as we were primarily interested in explaining differences in entrepreneurial activity from a geographic perspective. Regional variation in entry rates is often persistent (Fritsch and Mueller 2007; Brenner and Fornahl 2008) and the same can be expected from regional differences in entrepreneurial attitudes (Beugelsdijk 2007). Independent and dependent variables thus seem to reveal long-term and possibly pathdependent processes. Our dataset unfortunately does not allow us to disentangle the underlying dynamic mechanisms. Furthermore, it is necessary to include more and better indicators for demographic, economic and institutional determinants of both entrepreneurial attitude and entrepreneurial activity at the regional level.

Despite of the conceptual and empirical limitations of our study, our conclusions provide several recommendations for entrepreneurship policy. First, an entrepreneurial climate in which people tend to know other start-up entrepreneurs, and where people see good business opportunities and are aware of their own start-up skills and knowledge, triggers new entrepreneurship. Subjective feelings about entrepreneurship, or entrepreneurial perceptions, tend to be more important for starting businesses than objective regional characteristics. We realize that actively stimulating or creating such an entrepreneurial culture is far from easy, and takes time; but our empirical findings of a positive impact of favourable entrepreneurial perceptions are quite consistent for all entrepreneurship phases analysed. Perhaps policy efforts should be more directed towards positive entrepreneurial perceptions, successful business role models and positive attitudes towards entrepreneurship. Second, policy makers should not have high hopes of a direct influence of favourable regional economic features on regional entrepreneurship rates, as an indirect effect via regional entrepreneurial attitudes is much more plausible. Again, a long-term strategy is called for, as policy interventions such as labour market or GRP investments will only fuel actual entrepreneurship in the long term. And finally, in stimulating entrepreneurship rates national start-up procedures should be evaluated thoroughly as start-up burdens tend to lower the rate of established businesses.

Hope remains for national and regional policy makers, though. In particular our entrepreneurial network results (knowing many start-up entrepreneurs) imply that over time, entrepreneurial regions tend to reinforce entrepreneurship rates on their own. This suggests that despite the long-term effect of policy investments in a favourable regional entrepreneurial climate, beyond a certain entrepreneurship threshold regions may take over and generate new entrepreneurial spirits and entrepreneurial activity themselves.

Acknowledgments The authors would like to thank the audience at the ERSA 2007 conference (in Paris) and more in particular Rolf Sternberg, two anonymous referees, and the editor, for their valuable comments. Data for this study were provided by the Global Entrepreneurship Monitor (GEM), which is a consortium of research teams representing more than 60 nations across the globe. Names of the members of national teams, the global coordination team, and the financial sponsors are published in the annual Global Entrepreneurship Monitor Reports, which can be downloaded at http://www.gemconsortium.org. We thank all the researchers and their financial supporters who made this research possible. 
Open Access This article is distributed under the terms of the Creative Commons Attribution Noncommercial License which permits any noncommercial use, distribution, and reproduction in any medium, provided the original author(s) and source are credited.

\section{References}

Acs ZJ, I'Gorman C, Szerb L, Terjesen S (2007) Could the Irish miracle be repeated in Hungary? Small Bus Econ 28:123-142

Arenius P, Minniti M (2005) Perceptual variables and nascent entrepreneurship. Small Bus Econ 24:233247

Armington C, Acs ZJ (2002) The determinants of regional variation in new firm variation. Reg Stud 36(1):33-45

Audretsch DB, Fritsch M (2002) Growth regimes over time and space. Reg Stud 36(2):113-124

Audretsch DB, Keilbach M (2004) Entrepreneurship capital and economic performance. Reg Stud 38(8):949-959

Baskerville RF (2003) Hofstede never studied culture. Acc Organ Soc 28:1-14

Bergmann H (2002) Entrepreneurial attitudes and start-up attempts in ten German regions. An empirical analysis on the basis of the theory of planned behaviour, University of Cologne, Working Paper No. 2002-01

Bergmann H (2005) Entrepreneurial attitudes. Wodurch werden sie determiniert und welche Rolle spielt die Region? Zeitschrift für Wirtschaftsgeographie 49:185-199

Bergmann H, Japsen A, Tamásy C (2002) Regionaler Entrepreneurship Monitor (REM)_Gründungsaktivitäten und Rahmenbedingungen in zehn deutschen Regionen. Universität zu Köln and Universität Lüneburg

Bergmann H, Sternberg R (2007) The changing face of entrepreneurship in Germany. Small Bus Econ 28:205-221

Beugelsdijk S, Noorderhaven N (2004) Entrepreneurial attitude. Ann Reg Sci 38(2):199-218

Beugelsdijk S, Van Schaik T, Arts W (2006) Toward a unified Europe? Explaining regional differences in value patterns by economic development, cultural heritage and historical shocks. Reg Stud 40(3):317327

Beugelsdijk S (2007) Entrepreneurial culture, regional innovativeness and economic growth. J Evol Econ 17:187-210

Blanchflower DG (2000) Self-employment in OECD countries. Labour Econ 7:471-505

Blanchflower DG, Oswald A, Stutzer A (2001) Latent entrepreneurship across nations. Eur Econ Rev 45:680-691

Bosma NS, Schutjens VAJM (2007) Linking regional conditions to individual entrepreneurial behavior. Paper presented at the Babson Conference 2007, Madrid

Bosma NS, Schutjens VAJM (2009a) Mapping entrepreneurial activity and entrepreneurial attitudes in European regions. Int J Entrepreneurship Small Bus 7(2):191-213

Bosma NS, Schutjens VAJM (2009b) Determinants of early-stage entrepreneurial activity in European regions; Distinguishing low and high ambition entrepreneurship. In: Smallbone D, Landstrom H, Jones Evans D (eds) Making the difference in local, regional and national economies: frontiers in European entrepreneurship research. Edward Elgar, London, pp 49-77

Bosma NS, Jones K, Autio E, Levie J (2008) Global entrepreneurship monitor. 2007 Executive Report, Babson College and London Business School

Bosma NS, Acs ZJ, Autio E, Coduras A, Levie J (2009a) Global entrepreneurship monitor 2008, Executive Report, Babson College/Universidad del Desarrollo

Bosma NS, Schutjens VAJM, Stam FC (2009) Entrepreneurship in European regions: implications for public policy. In: Leitao J, Baptista R (eds) Public policies for fostering entrepreneurship. Springer, New York, pp 59-90

Bosma NS, Stam FC, Schutjens VAJM (2010) Creative destruction, regional competitiveness and policy. Small Bus Econ. doi:10.1007/s11187-009-9257-8

Brenner T, Fornahl D (2008) Regional path-dependence in start-up activity. Papers in Evolutionary Economic Geography nr. 08.12. Utrecht University, Utrecht

Davidsson P (1991) Continued entrepreneurship — ability, need, and opportunity as determinants of small firm growth. J Bus Venturing 6(6):405-426 
Davidsson P, Honig B (2003) The role of social and human capital among nascent entrepreneurs. J Bus Venturing 18(3):301-331

Davidsson P, Wiklund J (1997) Values, beliefs and regional variations in new firm formation rates. J Econ Psychol 18:179-199

De La Vega Pastor I, Coduras A, Cruz C, Justo R, Pia Nogueria M (2005) GEM Spain National Report (http://www.gemconsortium.org)

Delmar F, Davidsson P (2000) Where do they come from? Prevalence and characteristics of nascent entrepreneurs. Entrepreneurship Reg Dev 12(1):1-23

Douglas EJ, Shepherd DA (2002) Self-employment as a career choice: attitudes, entrepreneurial intentions, and utility maximization. Entrepreneurship Theory Pract 26(3):81-90

Etzioni A (1987) Entrepreneurship, adaptation and legitimation. J Econ Behav Organ 8:175-189

European Commission (2003) Green paper: entrepreneurship in Europe, Brussels: Enterprise Directorate General

Feldman MP (2001) The entrepreneurial event revisited: firm formation in a regional context. Ind Corp Change 10:861-891

Fotopoulos G, Louri H (2000) Location and survival of new entry. Small Bus Econ 14:311-321

Freytag A, Thurik R (2007) Entrepreneurship and its determinants in a cross-country setting. J Evol Econ 17:117-131

Fritsch M, Mueller P (2006) The evolution of regional entrepreneurship and growth regimes. In: Fritsch M, Schmude J (eds) Entrepreneurship in the region. International Studies in Entrepreneurship, 14. Springer, New York pp 225-244

Fritsch M, Mueller P (2007) The persistence of regional new business formation-activity over timeassessing the potential of policy promotion programs. J Evol Econ 17:299-315

Fritsch M (1992) Regional differences in new firm formation: evidence from West Germany. Reg Stud 26(3):233-241

Getis A, Ord JK (1992) The analysis of spatial association by use of distance statistics. Geogr Anal 24: 189-206

Grilo I, Irigoyen J-M (2006) Entrepreneurship in the EU: to wish and not to be. Small Bus Econ 26:305-318

Grilo I, Thurik R (2006) Latent and actual entrepreneurship in Europe and the US: some recent developments. Int Entrepreneurship Manage J 1:441-459

Hall PA, Soskice D (2001) Varieties of capitalism. The institutional foundations of comparative advantage. Oxford University Press, Oxford

Hofstede G (2001) Culture's consequences, 2nd edn. Sage, Thousand Oakes

Inglehart R (ed) (2003) Human values and social change: findings from the values surveys. Brill, Leiden

Inglehart R, Baker WE (2000) Modernization, cultural change, and the persistence of traditional values. Am Sociol Rev 65(1):19-51

Jonsson B, Flanagan C (2000) Young people's views on distributive justice, rights, and obligations: a crosscultural study. Int Social Sci J 52(164):195-208

Kirchhoff B, Armington C, Hasan I, Newbert S (2002) The influence of R\&D expenditures on new firm formation and economic growth. A Research Report for the US Small Business Administration by BJK Associate. Available at http://www.njit.edu/v2/News/Releases/finalreport_10-02-02.pdf. Accessed 27 Aug 2009

Kirkpatrick Johnson M (2001) Job values in the young adult transition: change and stability with age. Social Psychol Q 64(4):297-317

Koster S (2007) The entrepreneurial and replication function of new firm formation. J Econ Social Geogr TESG 95(5):667-674

La Porta R, Lopez-de-Silanes F, Shleifer A, Vishny R (1999) The quality of government. J Law Econ Organ, Oxford University Press 15(1):222-279

Lee SY, Florida R, Acs ZJ (2004) Creativity and entrepreneurship: a regional analysis of new firm formation. Reg Stud 38(8):879-891

Levie J (2007) Immigration, in-migration, ethnicity and entrepreneurship. Small Bus Econ 28:143-169

Liao J, Welsh H (2003) Social capital and entrepreneurial growth aspirations: a comparison of technology and non-technology-based nascent entrepreneurs. J High Technol Manage Res 14:149-170

Lückgen I, Oberschachtsiek D, Sternberg R, Wagner J (2006) Nascent entrepreneurs in German regions. In: Fritsch M, Schmude J (eds) Entrepreneurship in the region. International Studies in Entrepreneurship, 14. Springer, New York pp 7-35 
Malecki E (1997) Entrepreneurs, networks, and economic development: a review of recent research. In: Katz JA (ed) Advances in entrepreneurship, firm emergence and growth. JAI Press, Greenwich, pp 57-118

Minniti M, Nardone C (2007) Being in someone else's shoes: the role of gender in nascent entrepreneurship. Small Bus Econ 28:223-238

Mollenhorst G, Völker B, Schutjens V (2009) Neighbor relations in The Netherlands-a decade of evidence. J Econ Social Geogr TESG (forthcoming)

North DC (1994) Economic performance through time. Am Econ Rev 84(3):359-368

OECD (2004) Employment outlook, employment protection regulation and labour market performance. OECD, Paris

Parker SC (2005) Explaining regional variations in entrepreneurship as multiple equilibria. J Reg Sci 45:829-850

Peters M, Cressy RC, Storey DJ (1999) The economic impact of ageing on entrepreneurship and SMEs. Warwick Business School/EIM, Warwick/Zoetermeer

Reynolds PD, Bosma N, Autio E, Hunt S, de Bono N, Servais I, Lopez-Garcia P, Chin N (2005) Global entrepreneurship monitor: data collection design and implementation 1998-2003. Small Bus Econ 24(3):205-231

Rocha HO, Sternberg R (2005) Entrepreneurship: the role of clusters. Theoretical Perspectives and Empirical evidence from Germany. Small Bus Econ 24:267-289

Saxenian A (1999) Silicon Valley's new immigrant entrepreneurs. Public Policy Institute of California, San Francisco

Schutjens VAJM, Wever E (2000) Determinants of new firm success. Papers Reg Sci 79(2):135-153

Schutjens VAJM, Stam FC (2003) The evolution and nature of young firm networks: a longitudinal perspective. Small Bus Econ 21(2):115-134

Siegfried JJ, Evans JB (1994) Empirical studies on entry and exit: a survey of the evidence. Rev Ind Organ 9:121-155

Sternberg R (2004) Entrepreneurship research - the relevance of the region and tasks facing economic geography. Geographische Zeitschrift 92:18-38

Sternberg R (2009) Regional dimensions of entrepreneurship. Found Trends Entrepreneurship 5(4): 211-340

Sternberg R, Litzenberger T (2004) Regional clusters in Germany. Eur Plan Stud 12(6):767-791

Sternberg R, Wagner J (2005) Zur Evidenz regionaler Determinanten im Kontext individueller Gründungsaktivitäten. Zeitschrift für Wirtschaftsgeographie 49:167-184

Stevenson L, Lundström A (2001) Entrepreneurship policy-making: Frameworks, approaches and performance measures. International Council for Small Business, 47th World Conference

Stuart T, Sorenson O (2003) The geography of opportunity: spatial heterogeneity in founding rates and the performance of biotechnology firms. Res Policy 32:229-253

Tamásy C (2006) Determinants of regional entrepreneurship dynamics in contemporary germany: a conceptual and empirical analysis. Reg Stud 40(4):364-384

Tödtling F, Wanzenböck H (2003) Regional differences in structural characteristics of start-ups. Entrepreneurship Reg Dev 15:351-370

Uhlaner L, Thurik R (2007) Postmaterialism influencing total entrepreneurial activity across nations. J Evol Econ 17:161-185

Van Stel A, Storey DJ, Thurik AR (2007) The effect of business regulations on nascent and young business entrepreneurship. Small Bus Econ 28:171-186

Weber M (1904) The protestant ethic and the spirit of capitalism, translated by T. Parsons. Scribner, New York (1929)

Wennekers ARM (2006) Entrepreneurship at country level: economic and non-economic determinants. Dissertation, ERIM Erasmus University Rotterdam

Wennekers A, Thurik R, Van Stel A, Noorderhaven N (2007) Uncertainty avoidance and the rate of business ownership across 21 OECD countries, 1976-2004. J Evol Econ 17:133-160

World Bank (2005) Doing business in 2005: removing obstacles to growth. World Bank, Washington DC 